\title{
Tres décadas de proyectos e investigaciones arqueológicas en la Universidad de Alicante.
}

\author{
A Manuel BENDALA GALÁN, \\ maestro, compañero, amigo \\ Lorenzo ABAD CASAL (L.A.) Sonia GUTIÉRREZ LLORET (S.G.); Carolina DOMÉNECH BELDA C.D.), \\ Antonio ESPINOSA RUIZ (A.E.), Ignasi GRAU MIRA (I.G.); Jesús MORATALLA JÁVEGA (J.M.), \\ Fernando PRADOS MARTÍNEZ (F.P.), Feliciana SALA SELLÉS (F.S.). ${ }^{1}$ Universidad de Alicante.
}

\section{Resumen}

En las últimas décadas, la Arqueología de investigación realizada desde el Área de Arqueología de la Universidad de Alicante ha realizado considerables aportaciones en el ámbito transversal de la Arqueología, desde el convencimiento de que esta disciplina no debe estar atada a ningún periodo histórico concreto. Así, se ha propuesto una nueva visión urbanística de los primeros tiempos de la cultura ibérica y de su relación con la fenicia; se han identificado y estudiado ciudades romanas hasta ahora desconocidas y se han desarrollado modelos del cambio cultural que desde la tardía Antigüedad lleva al Medievo.

Palabras clave: Arqueología, cultura ibérica, romanización, cambio cultural, islamización

\section{Summary}

In the last decades, the archaeological research done by the Archaeology Department of the University of Alicante has contributed greatly to this field, convinced that this discipline should not be tied to any particular historical period. Therefore, a new urbanistic view of the early days of the Iberian culture and its relation to Phoenician culture has been proposed. New Roman cities, unknown until these days, have been identified and studied, and new models of cultural change from Late Antiquity to the Middle Ages have been developed.

Keywords: Archaeology, Iberian culture, Romanization, cultural change, Islamization.

\section{Manuel Bendala y la arqueología ALICANTINA (L.A.)}

Al contribuir al homenaje a Manuel Bendala Galán, en la revista del que ha sido su centro de actividad durante muchos años, hemos querido presentar un trabajo redactado por todos los que componemos el Área de Arqueología de la

1 Los firmantes son los miembros del Área de Arqueología de la Universidad de Alicante, que forman también el grupo de investigación Arqueología y Patrimonio Histórico de la misma universidad. El trabajo presentado es
Universidad de Alicante, vinculados de una u otra forma a su docencia, a su magisterio y, sobre todo, a su amistad. Somos todos los que estamos, pero no estamos todos los que somos. Colegas, discípulos y compañeros que en algún momento han compartido algo de todo ello, se suman también de buena gana a la intención de este trabajo. 
Manuel Bendala estuvo presente en los albores del desarrollo de la Arqueología en la Universidad de Alicante. Con él llevamos a cabo las primeras campañas de excavación y contribuyó muy activamente a despertar la pasión por la arqueología de no pocos de nuestros primeros alumnos. Su facilidad para el dibujo ayudó también a educar la mano de los más diestros, en un momento en que el dibujo por ordenador ni siquiera estaba en la mente de sus creadores. La relación entre las Áreas de Arqueología de la Universidad de Alicante y de la Universidad Autónoma de Madrid no se ha interrumpido con el paso del tiempo; hemos seguido compartiendo tanto la visión académica de la Arqueología como la preocupación por su presente y su futuro.

Por eso hemos querido que nuestra colaboración en el Homenaje que cierra su faceta como profesor en activo, que no como profesor ni como investigador, sea un empeño común de un grupo de personas que comparten un lugar de trabajo, pero que sobre todo comparten un interés por la Arqueología, una forma de entenderla y una forma de afrontar sus problemas, sus retos y sus ilusiones.

En el verano de 1981 iniciamos el proyecto del Poblamiento Ibérico en el Bajo Segura. Nuestra intención era estudiar algunos de los yacimientos que salpicaban la margen izquierda del río, pues en la derecha un equipo hispano-francés, compuesto por Enrique Llobregat, Carmen Aranegui, Pierre Rouillard, André Jodin y José Uroz, comenzaban la excavación del poblado y la necrópolis del Cabezo Lucero; unos eran conocidos, como La Escuera, excavada por Solveig Nordström en el año 1960 y publicado algún tiempo después; otros permanecían inéditos, y entre ellos elegimos dos: el Castillo de Guardamar y El Oral.

Para la excavación de estos tres yacimientos se formó un equipo conjunto de la Universidad de Alicante y de la Universidad Autónoma de Madrid que se mantuvo hasta el final de los trabajos en 1986, cuando la revalorización que ya por entonces comenzaban a experimentar los terrenos de la Vega Baja del Segura obligó a cerrar las excavaciones. Los arqueólogos que trabajaban en áreas de interés urbanístico resultaban huéspedes poco deseados, a los que se llegó a desalojar escopeta en mano. Aun así, como resultado de aquellas actuaciones, se consiguió salvar el yacimiento de La Escuera, hoy último reducto de la naturaleza en la frontera de un mar de urbanizaciones.

\section{EN BUSCA DE LO IBÉRICO ENCONTRAMOS A LOS FENICIOS... (L.A., F.S., F.P.)}

El Castillo de Guardamar no respondió a nuestras expectativas, pues el área donde excavamos había sido removida y alterada por edificaciones militares modernas. No obstante, las prospecciones por la ladera pudieron completar el conjunto de pebeteros en forma de cabeza femenina que había comenzado a reunir el Grupo Arqueológico de Rojales y permitió añadir un punto a la serie de santuarios costeros vinculados a los cursos de agua y a la navegación (Abad Casal, 2010b).

La actividad en El Oral resultó, en cambio, mucho más fructífera, tanto en esta primera fase como en la que iniciamos en 1990, ahora ya en colaboración con Feliciana Sala (Abad Casal y Sala Sellés, 1993; Abad Casal y Sala Sellés, 2001). Desde el primer momento, El Oral sorprendió tanto por las estructuras que aparecían como por los materiales que proporcionaba; éstos eran escasos, resultado de un proceso de abandono no violento, pero se diferenciaban de lo habitual en otros poblados ibéricos de la zona y tampoco correspondían a los que por entonces comenzaba a descubrir Alfredo González Prats en la Sierra de Crevillente, aunque mostraran relaciones con unos y otros. Cerámicas de almacenamiento, de cocina y de mesa; formas poco corrientes en poblados, como urnas de orejetas, platos grises de inspiración fenicia y materiales de alto valor, como huevos de avestruz, un jarro etrusco, un rallador y varios alfinetes, nos hacían pensar que la escasez de material no era sinónimo de pobreza. Todo ello, además, datado en las últimas décadas del siglo VI a.C., una fecha que hacía la cultura ibérica bastante más antigua de lo que hasta entonces se había supuesto.

Más significativo aún era que El Oral mostraba un complejo urbanismo trazado en un solo momento y una desarrollada arquitectura de mampostería, adobe y tapial. Destacaba sobre todo su importante equipamiento urbano hecho de tierra, a veces polícroma: canales revestidos de conchas que desaguaban a través de la muralla, bancos, hogares de varios tipos y diversa composición, un pavimento decorado en forma de lingote chipriota o piel de toro, etc. Ante nosotros aparecía un urbanismo y una arquitectura desconocidos por entonces en la 
cultura ibérica, de una fecha bastante antigua, que no resultaba fácil de interpretar. El Oral no sólo arrinconaba la idea tradicional de una arquitectura y urbanismo ibéricos más bien pobres (Abad
Casal y Bendala Galán, 1994; 1997), sino que postulaba una estrecha relación con el concepto de ciudadanía urbana gestado y compartido por las culturas mediterráneas del I milenio a.C. (Fig. 1).

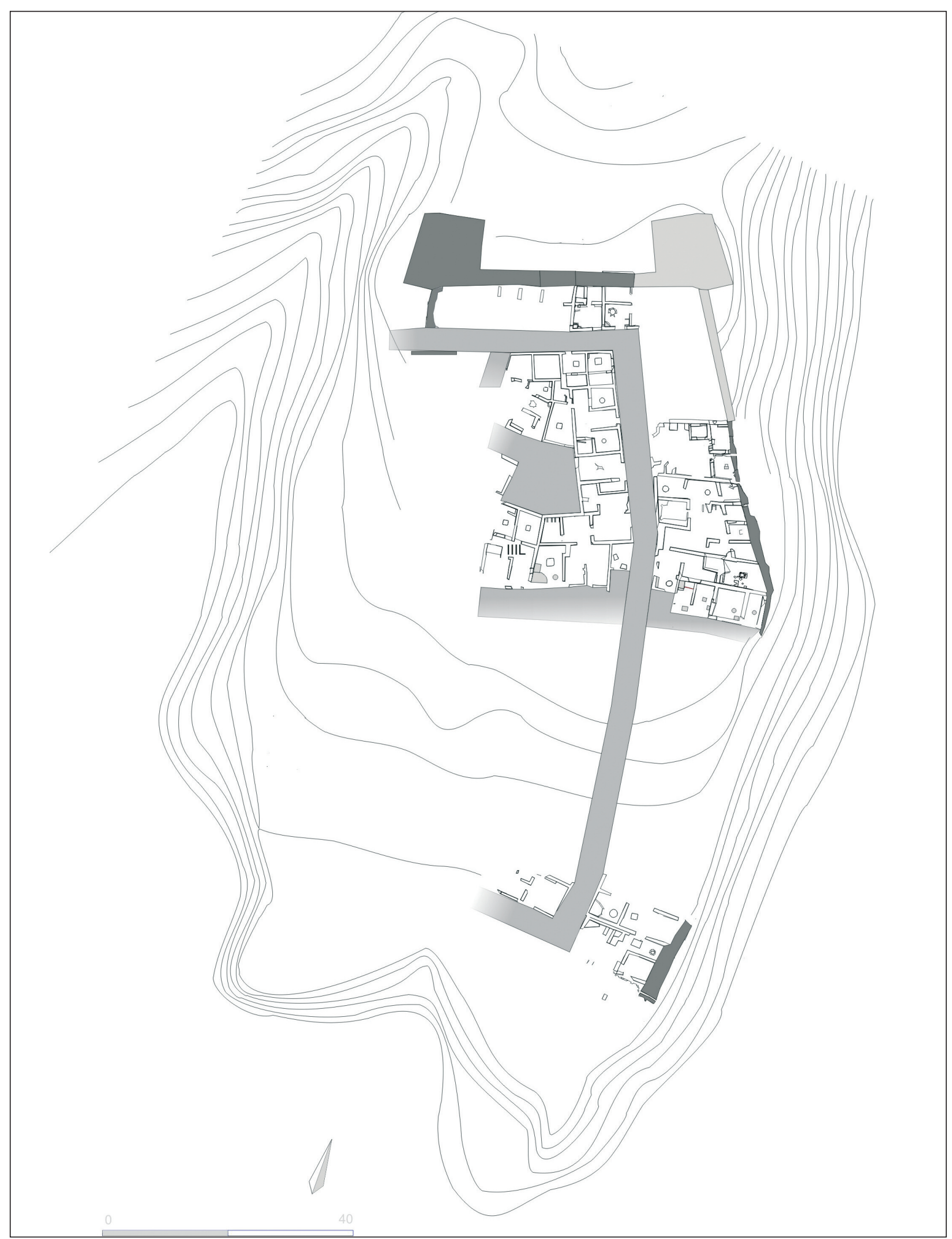

Figura 1. Planimetría del poblado de El Oral. 
Quizás la imagen que mejor lo define sea la del oikistés que al frente de su pequeña comunidad se afana en poner en marcha el proyecto fundador del enclave; una imagen con la que Manuel Bendala iniciaba un ejercicio de reconstrucción histórica, riguroso con los datos, y que ha servido para que hornadas de alumnos y de lectores de historia puedan entender mejor alguno de los mecanismos de actuación de los pueblos (Bendala Galán, 2000, 183-198).

Hoy, con la perspectiva que el tiempo nos da, y con las nuevas aportaciones realizadas a la cultura ibérica, también nosotros podemos entender mucho mejor lo que significa este poblado. El Oral se puede enmarcar de manera global dentro del paisaje urbano mediterráneo y es heredero de la tradición constructiva oriental y orientalizante. Ello se intuye gracias a ciertos rasgos arquitectónicos tan significativos como el uso de un patrón de medida similar al codo púnico y al empleo de unas fábricas constructivas de barro ciertamente complejas. También gracias a su urbanismo y al reparto del espacio residencial, planificado con antelación a partir de modelos ya ensayados. Tal vez no sea mera casualidad que uno de los modelos más próximos al urbanismo de El Oral sea la acrópolis de la ciudad púnica de Monte Sirai, en Cerdeña. Las casas de El Oral presentan una arquitectura doméstica de aire mediterráneo inconfundible, en sus equipamientos y en su variado repertorio, desde casas sencillas a grandes casas con patio central, variedad que refleja una interesante diferenciación social (Sala Sellés y Abad Casal, 2006). Las referencias originales de esta arquitectura estaban en asentamientos fenicios y protohistóricos del mediodía peninsular, pero la excavación de la colonia fenicia de la Fonteta, en Guardamar (Rouillard et alii, 2007; González Prats, 2010), frente a El Oral, en el lado opuesto de la desembocadura del río Segura, ha puesto ante nosotros una arquitectura doméstica muy similar, lo que ha permitido despejar las dudas acerca de la raíz oriental de la primera arquitectura ibérica contestana. Bien es cierto que hay que andar todavía con cuidado; no podemos olvidar que los escasos vestigios arquitectónicos y de equipamiento encontrados en la Ampurias de la época reflejan un ambiente cultural bastante parecido.

Sea como fuere, el área del Bajo Segura se considera hoy un referente para el cambio cultural generado desde fines del siglo VIII a.C. por la convivencia entre comunidades fenicias y la protohistórica local. Ese contexto de relaciones estables eclosionó en las últimas décadas del siglo VI a.C. en la cultura ibérica que vemos en El Oral. Procesos de mestizaje e hibridación han sustituido al de aculturación para explicar la transformación cultural (Aranegui Gascó y Vives-Ferrándiz, 2006). Teorías que explicarían mejor la arquitectura orientalizante de El Oral, ya que la población fundacional bien podría descender del viejo enclave fenicio, abandonado seguramente por causas medioambientales, mestizada con la población local (Abad Casal y Sala Sellés, 2009).

Hoy no es posible estudiar la cultura ibérica sin el concurso de la púnica, y en esta línea se ha trabajado bastante en los últimos años (por ejemplo Mata Parreño, 1995; Moret, 2006; Oliver Foix, 1995; Sala Sellés, 2004). Pero han sido las propuestas de M. Bendala (2009) las que más han aproximado la tradición ibérica al mundo púnico. Como los fenicios unos siglos atrás, creemos que también los púnicos convivieron con los iberos de la costa contestana en el marco de unas actividades económicas provechosas para ambas comunidades. Conocemos las fechas probables, entre los siglos V y III a.C., y también alguna de las circunstancias que lo provocaron, como la segunda guerra púnica. Nuestro reto para el futuro es identificar el rastro material de dicha convivencia, y a ello se han aplicado una parte de los firmantes.

El estudio de los materiales y de su significado es un proceso en marcha, que no requiere justificación, pero está claro que la presencia de materiales no prueba por sí misma una relación directa. Hay que recurrir a otros parámetros, y entre ellos -una vez más las ideas de Manuel Bendala -destacan las tradiciones constructivas como rasgo identificativo de las culturas; podemos aplicar a la cultura ibérica el concepto de "cultura arquitectónica" por él acuñado y defendido. Sistematizar y dar contenido a la cultura arquitectónica ibera ayudaría a seguir su rastro en las "culturas arquitectónicas" foráneas, algo que ha comenzado a hacer F. Prados (2007; 2011) con algunos monumentos funerarios contestanos (Fig. 2).

El descubrimiento de esta impronta púnica y la aceptación de su importancia en la conformación de la cultura ibérica es una de las aportaciones de los arqueólogos que trabajamos en el territorio al que por comodidad, y también por coherencia, aplicamos la denominación clásica de Contestania. 


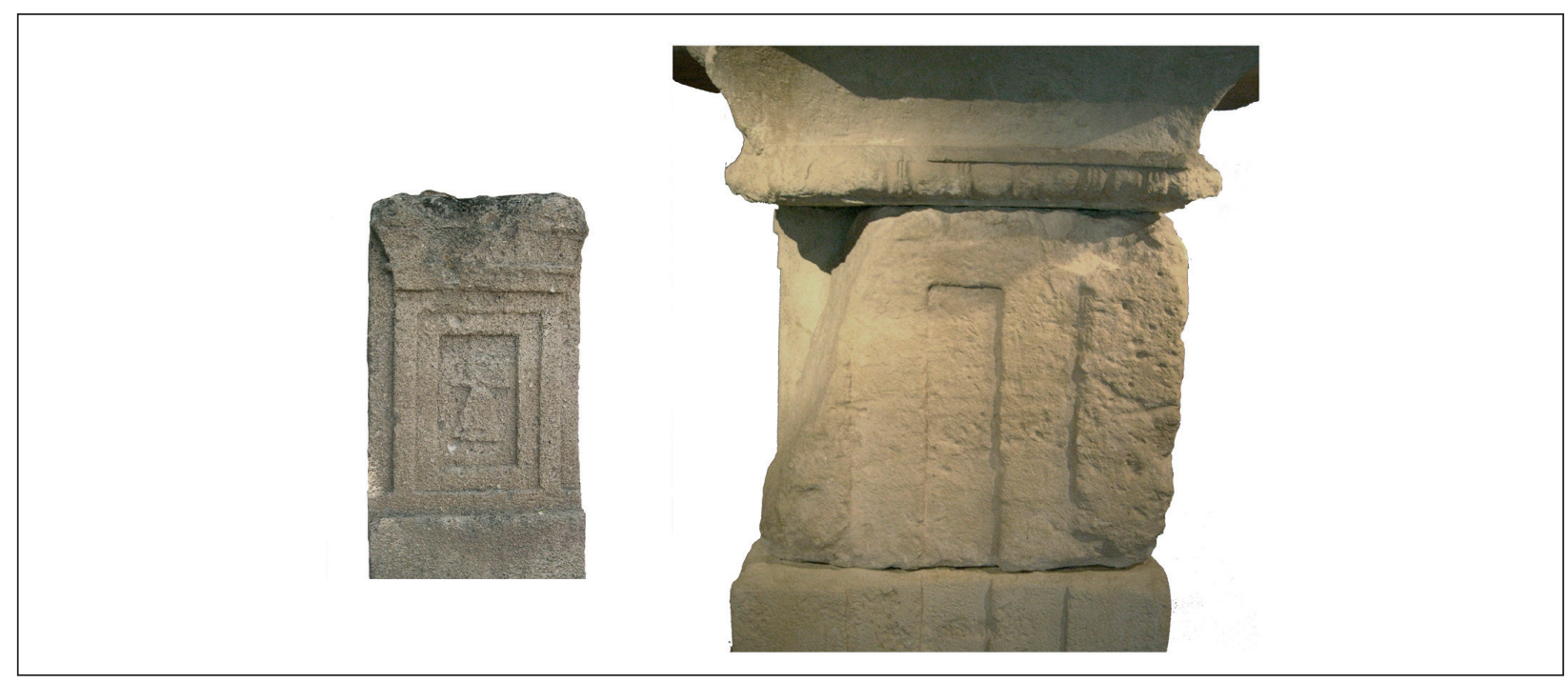

Figura 2. Detalle de una estela del tofet de Cartago y del pilar-estela de Monforte del Cid

A día de hoy, este ámbito presenta en su litoral meridional un conjunto de enclaves costeros en los que la convivencia entre púnicos e iberos fue un hecho, en diversas circunstancias y en distintos momentos entre los siglos V y III a.C. No descartamos que se alargara hasta los siglos II y I a.C.

El registro arqueológico que han puesto al descubierto los trabajos de los últimos años en esos enclaves no resulta fácil de interpretar si no es así: la Illeta dels Banyets y el Tossal de Manises en el entorno de l'Albufereta, y El Oral y La Escuera en la desembocadura del Segura, se incluyen en esta relación; son lugares en los que las buenas condiciones para el refugio de naves favoreció su consolidación como escenario de encuentros. Es una nueva visión, más acorde sin duda con los procesos históricos, que se ha presentado en el VI Coloquio del Centro de Estudios Fenicios y Púnicos (Olcina Doménech et alii, 2010; Sala Sellés, 2010; Verdú Parra, 2010). Sin embargo, aún hay mucho que trabajar para superar las reticencias de algunos investigadores a aceptar este nuevo marco histórico, algo por otra parte perfectamente comprensible en el cuadro de la historiografía alicantina del siglo XX, un escenario que es preciso recordar.

Hasta hace pocas décadas, buena parte de los estudios sobre el mundo púnico se desarrollaban con la intención de buscar respuesta al porqué del ocaso de la civilización tartésica, apoyándose en

2 Para una descripción más detallada de este momento de la historiografía alicantina debe consultarse el libro ya clásico un mito cultural gestado a partir del siglo XVII. Esta decadencia fue explicada por algunos como consecuencia de una acción directa púnica que supuso el final de la floreciente Tartessos, que ocupaba todo el tercio sur de Iberia (Schulten, 1924). En cambio, en el área alicantina el debate de los historiadores locales se centró en la identificación de la mítica Akra Leuke de Diodoro en las proximidades de la ciudad de Alicante. Lafuente desarrollo sus teorías sobre la presencia púnica en territorio alicantino en su obra de 1957, Alicante en la Edad Antigua, proponiendo la localización de la fundación de Amílcar Barca en el monte Benacantil, junto a la ciudad actual. Figueras publicaba en 1959 la síntesis de todos sus trabajos anteriores, Dos mil años atrás. Las ciudades, el puerto y la necrópolis de La Albufereta, y en ella reiteraba su identificación de Akra Leuke con los restos arqueológicos del Tossal de Manises, en el entorno de l'Albufereta. Como epígono de esta arqueología de corte filológico, la arqueóloga sueca Solveig Nordström, en Los cartagineses en la costa alicantina, insistía en la incidencia púnica en la Contestania y en la directa relación con el mundo púnico de muchos objetos arqueológicos que aparecían en los yacimientos ibéricos alicantinos excavados por entonces; incluso llegó a proponer traslados de población, al interpretar la necrópolis del Molar como consecuencia de una invasión cartaginesa en la costa alicantina (Nordström, 1961). ${ }^{2}$

de L. Abad de 1984 y los artículos de F. Sala de 2001-2002 y 2005. 
En los años siguientes, y como reacción a esta tendencia, se produjo un movimiento pendular en la interpretación histórica y arqueológica. Su abanderado fue Enrique Llobregat, que en 1969 iniciaba un proceso de desmitificación de las tesis cartaginesistas anteriores (Llobregat Conesa, 1969), al tiempo que ponía el acento en el carácter autóctono de la cultura ibérica. Su Contestania Ibérica proponía por primera vez la caracterización de una regio ibérica desde el punto de vista arqueológico (Llobregat Conesa, 1972) y explicaba los objetos de procedencia púnica en los yacimientos contestanos como resultado de unos contactos comerciales que no habían tenido mayores consecuencias.

Treinta años después, sin embargo, el péndulo vuelve a equilibrarse; la identificación del fortín del Tossal de Manises y su relación con las aspiraciones territoriales de los generales cartagineses nos lleva de nuevo al viejo debate historiográfico sobre el fundador y el nombre de la fundación: Amílcar Barca o Asdrúbal Barca, Akra Leuke o la fundación de nombre desconocido de Asdrúbal; pero ahora, a diferencia de lo que ocurría entonces, partimos de una sólida base arqueológica producto de años de investigación sobre el terreno. El 'responsable' de este proyecto, Manuel Olcina, se decanta por la segunda opción, aunque sin cerrar la puerta a la primera porque, en rigor, no se conocen testimonios arqueológicos que ubiquen con certeza la fundación de Amílcar en la zona de Cástulo (Olcina Doménech, 2005, 164). Pero el péndulo todavía no se ha detenido y en los próximos años veremos interesantes novedades. Ahora volveremos atrás y retomaremos otro hilo del discurso que antes apuntábamos.

\section{El PROBlema de loS Fósiles directo- RES, LAS CRONOLOGÍAS Y SU INTERPRETA- CIÓN (J.M.)}

Hoy los investigadores están de acuerdo en que la existencia de una cultura material bien definida a partir del registro de El Oral permite denominar ibérica a la cultura que ocupaba este territorio entre el 525 y el 450 a.C. Los poblados que grosso modo presentan su ajuar-tipo pasan a encuadrarse en esa fase establecida y los que no, se colocan en una horquilla posterior que alcanzaría hasta el 325 a.C.; este mismo proceso se va repitiendo hasta la conquista romana, que cuenta ya con fechas absolutas transmitidas por fuentes escritas. Si reflexionamos en torno a ello, caere- mos en la cuenta de que posiblemente este encaje tan ordenado y diríamos que incluso matemático podría no ser del todo correcto, pues se antoja poco creíble esta sucesión casi lineal de una serie de asentamientos completamente sincrónicos.

Nuestra pregunta es si no estamos sobrevalorando la importancia cronológica que damos al registro material que sirve de base a este planteamiento, basada en la datación propuesta para determinados envases cerámicos importados, especialmente vajilla de mesa y recipientes anfóricos, y que determina por ejemplo, que todo contexto con vasos áticos de los siglos V-IV a.C., se sitúe de forma casi automática en la fase que venimos a llamar Ibérico Pleno. El final de este periodo se ubica en una horquilla que iría del 330 al 300 a.C., sin que existan argumentos claros -por mucho que se haya discutido- sobre las razones de este hiatus. Y se trata de una ruptura que, en la historia de los iberos, afecta a prácticamente todo el territorio y provoca el fin de no pocos asentamientos.

Conforme avanza la secuencia, las dataciones se vuelven más precisas, debido, por un lado, a la precisión cronológica que aportan las fuentes escritas a partir de la narración de los episodios ligados a la segunda guerra púnica y a los sucesos posteriores, y por otro a un mejor conocimiento del repertorio cerámico estrictamente romano. Hoy estamos en condiciones de poder datar prácticamente en el margen de una década muchos yacimientos del llamado periodo Ibérico Tardío, que antaño se situaba también cómodamente entre los siglos II y I a.C. Ello nos ha permitido valorar la ocupación de los asentamientos desde una óptica más concreta y proponer el hecho histórico que pudo contribuir a su abandono. Podríamos añadir que la precisión de los materiales romanos confirma continuamente la amplia perdurabilidad de los recipientes cerámicos, sin que sea raro ver convivir envases manufacturados con un siglo de diferencia, y ello en una sociedad ciertamente avanzada en cuanto a tecnología y producción cerámica.

A partir de la segunda guerra púnica se están dando, por lo tanto, las condiciones necesarias para concatenar con precisión los datos históricos $\mathrm{y}$ arqueológicos, y ya no resulta aventurado relacionar, por ejemplo, la fundación de la primera ciudad del Tossal de Manises con un proyecto bárquida fraguado en torno al 230-226 a.C., o que determinados enclaves de la Marina Alta - verbi- 
gracia la Penya de l'Àguila o Segària - aparezcan estrechamente vinculados a los episodios bélicos ligados a la lucha entre Sertorio y Pompeyo (8372 a.C.). Estos planteamientos muestran lo que podríamos denominar "el rostro de la historia"; van más allá de una "estática" sucesión por fases que puede ser incorrecta y documentan un hecho demográfico que no se toma muy en cuenta en los análisis genéricos al uso: los asentamientos pueden tener una muy corta vida. La fase prerromana del Tossal de Manises no se extendió más allá de un par de décadas y los hitos señalados en el entorno de Denia debieron estar ocupados apenas una ${ }^{3}$.

Frente a este dinamismo en la población, que viene en gran parte condicionado por la presencia de ejércitos extranjeros en territorio ibérico, lo que conocemos como periodo ibérico pleno queda aletargado, casi sin conexión con la población que conoció la presencia bárquida en sus tierras. En efecto, el poblamiento local de dos terceras partes del siglo III a.C. queda en sombra, al menos en territorio contestano; la contundente cesura temporal del último tercio de la centuria anterior, como hemos señalado, afectaría a la totalidad de la red demográfica implantada, aunque nunca se haya hilado un argumento explicativo que logre un mínimo consenso en la investigación. Lo que ahora pretendemos es someter a juicio este hiatus cronológico y considerar como artificial la división temporal tan rotundamente establecida.

Creemos que existen muchas probabilidades de que no todos los asentamientos que consideramos del periodo ibérico pleno fueran por completo sincrónicos. Debieron existir distintas fórmulas de ocupación; a veces ésta no iría más allá de unas décadas y en cambio es posible que aquellos que damos por abandonados hacia el último cuarto del siglo IV a.C. perduraran en la centuria siguiente. El responsable no es otro que el 'fósil director', la cerámica ática, que impulsa a datar en el siglo IV a.C., sin plantear una posible perduración, todo asentamiento que ofrezca esta vajilla, sin tener en cuenta que un ajuar tan valioso debió estar en uso varias décadas; no sólo por su valor intrínseco, sino por la notable escasez de piezas de mesa similares de la primera mitad del siglo III a.C. Es

3 Varios de estos establecimientos parecen construcciones militares levantadas en unas circunstancias muy determinadas, un hecho de gran interés que se encuentra actualmente posible que estemos sobrevalorando la información aportada por ese tipo de cerámica y que esos productos perduren en la primera mitad de la siguiente centuria, como recipientes valiosos que todavía no han sido sustituidos. Algo similar a lo que ocurre con las monedas romanas en contextos islámicos, como tendremos ocasión de tratar páginas más adelante.

Hay datos que apuntan esta posibilidad e indicios que parecen señalar el mismo camino. Las investigaciones realizadas por el MARQ en los últimos años en el yacimiento de La Illeta de El Campello certifican una ocupación hasta prácticamente mediados del siglo III a.C., retrasando su fin un par de generaciones respecto a lo considerado hasta hace apenas una década; y lo mismo se adivina en las primeras noticias publicadas sobre el Tossal de les Basses, que parece que se abandona para ocupar la nueva ciudad levantada en el Tossal de Manises. Un indicio puede ser también que una necrópolis ampliamente estudiada como la de Cabezo Lucero, cuyas últimas incineraciones se sitúan hacia el 325 a.C., cuente en su repertorio material con tres monedas de origen ebusitano, que serían las monedas más antiguas de esta ceca, encontradas además fuera de la isla. Convendría plantearse la posibilidad de que se trate en realidad de un hallazgo del siglo III a.C., aunque ello obligara a prolongar en el tiempo el uso del campo funerario.

Quedaría por comprobar el papel desempeñado por hitos en apariencia tan relevantes como La Alcudia de Elche o El Monastil de Elda, presumiblemente ocupados en todo momento y centros nucleares de su comarca, o la secuencia precisa que puede proveer un asentamiento tan singular como La Escuera. Igualmente resta por considerar los asentamientos que ofrecen una a priori inequívoca ocupación durante el siglo IV a.C., como podrían ser La Picola o El Puntal de Salinas, valorando tanto la hipótesis de que su ocupación fuera más corta de lo que realmente se postula como la de que se proyectara durante algunas décadas dentro del siglo III a.C.

Proponemos, en resumen, una relectura de la estructura cronológica que hemos venido construyendo a partir de una serie de análisis de tipo diacró-

en estudio. Incluso es sugerente reflexionar acerca de si este tipo de asentamientos no estarían ya presentes en centurias anteriores a llegada de los Barca. 
nico y que ha encorsetado en exceso el desarrollo histórico de una comunidad antigua, camuflándola tras de una serie de tablas de las que estaría ausente su historia. Justo al contrario, creemos, de lo que Manuel Bendala proponía en un libro que precisamente por ello alcanzó un considerable éxito y cuyo mensaje es hoy más actual que nunca (Bendala Galán, 2000).

\section{Los paisajes de la Contestania y la ARQUEOLOGÍA. REFLEXIONES DESDE EL POBLAMIENTO (I.G.)}

Volvamos ahora al proceso histórico. La configuración territorial del mundo ibérico ha sido un aspecto de gran desarrollo en la investigación arqueológica de las últimas décadas en el ámbito que en la literatura arqueológica denominamos frecuentemente Contestania ibérica. Las bases las pusieron en los años setenta y ochenta unos trabajos que esbozaron las líneas a seguir: la Contestania Ibérica de E. Llobregat (1972) y la contribución de L. Abad al coloquio sobre los Iberos de Jaén (Abad Casal, 1987). En ambas obras se presentaba la mayor parte de los asentamientos que aún en la actualidad constituyen la horma básica del poblamiento ibérico de la zona y se planteaban hipótesis sobre la estructura territorial que futuros trabajos específicos debían desarrollar. Los análisis posteriores han incorporado un buen caudal de datos procedentes de trabajos de campo y el desarrollo de nuevos modelos teóricos y métodos de análisis espacial, en particular la aplicación de los SIG, han permitido avanzar considerablemente en este camino.

\section{Del poblado al oppidum: el territorio local}

La investigación tradicional sobre el poblamiento ibérico reconocía la existencia de variedad de hábitats con formas, extensiones y emplazamientos diversos, Sin embargo, el énfasis se colocaba en cada una de las unidades básicas, más o menos autónomas, que se describían de forma neutra con la denominación de "poblado". Ese panorama se renueva conceptualmente a partir de los años ochenta con la aparición del concepto de redes de poblamiento, presididas por enclaves principales que dominan sus respectivos territorios. Es un esquema propuesto por primera vez para el territorio de Edeta (Bernabéu et alii, 1987) y que sirvió de modelo para los siguientes análisis en nuestra zona de estudio.
La Contestania muestra un denso poblamiento ibérico cuya unidad principal es un tipo de poblado agregado, fortificado y con tamaño entre 1,5 y 4 ha, al que denominamos oppidum. Los oppida presiden unidades de paisaje locales por cuyos llanos se emplazan asentamientos de pequeño y mediano tamaño que constituyen núcleos campesinos dependientes (Grau Mira, 2002, 240-246; Moratalla, 2005).

Este modelo de poblamiento surge de una retícula de pequeños territorios yuxtapuestos, entre los que emergió un oppidum de mayor tamaño que aglutinó las funciones de representación social y decisión política a modo de capital (Fig. $3)$. Son procesos de centralización política que se desarrollaron desde el siglo IV a.C. en torno a Ilici (Moratalla Jávega, 2005) y hacia el siglo III a.C. en torno a La Serreta (Olcina Doménech et alii, 1998; Grau Mira, 2002) y Saitabi (Pérez Ballester y Borreda, 1998; Grau Mira, 2005). Procesos similares debieron darse en los territorios albaceteños y murcianos de la Contestania. En el primer territorio se plantean dinámicas semejantes en torno a oppida como El Tolmo, Peñarrubia o El Castellar de Meca (Soria Combadiera, 2000), mientras que en las comarcas murcianas, en las que este proceso de investigación arqueológica está dando sus primeros pasos, contamos ya con propuestas generales (García Cano, 1997, 27) y un estudio de detalle de las comarcas más occidentales (López Mondéjar, 2008).

\section{La escala de los oppida contestanos}

Los oppida de la zona de estudio, tanto los centros de poder locales como los que ejercerían las funciones de capitales comarcales, se distinguirían en el panorama de centros urbanos ibéricos por su reducido tamaño. Han sido definidos como micronúcleos por A. Ruiz, en su propuesta de diferenciación de las trayectorias de urbanización en Iberia (Ruiz, 2007). No es un hecho anómalo: la media de las poblaciones antiguas del área no ha sido nunca demasiado grande y cuando se consolidó el proceso de urbanización con la aparición de las ciudades romanas, tampoco tuvieron grandes superficies. Ilici alcanzaría las 6 ha (Moratalla Jávega, 2004-2005), Ilunum tendría aproximadamente 7 ha (Abad Casal, 2006) y Lucentum tan sólo 3,5 ha (Olcina Doménech, 2009), estando por determinar aún la extensión de la ciudad romana de Villajoyosa. 


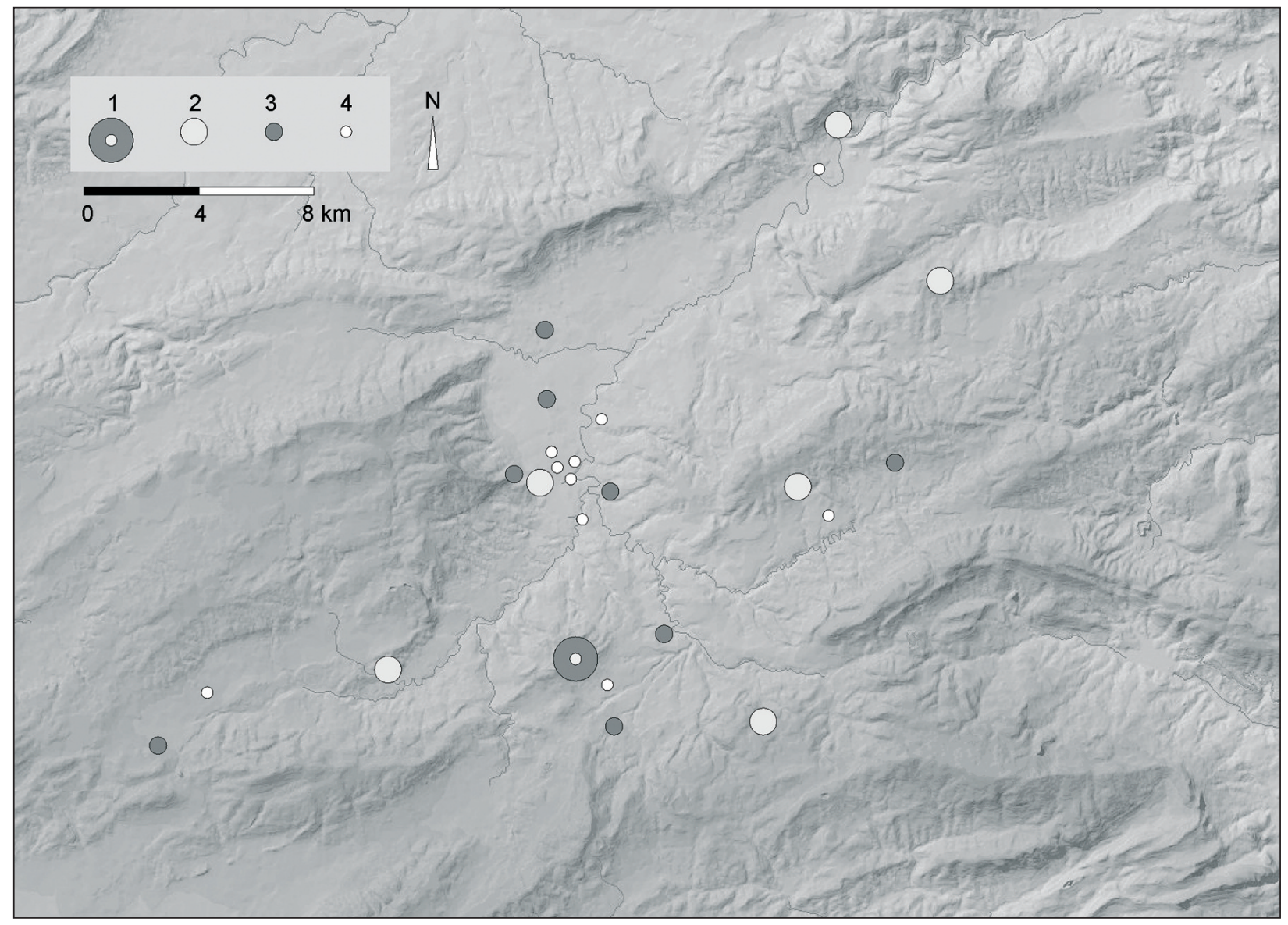

Figura 3. Estructura del territorio presidido por la ciudad de la Serreta en el s. III aC. 1: Ciudad de La Serreta;

2: Oppida secundarios; 3: Aldeas; 4: Caseríos.

Es posible que ese reducido tamaño de los núcleos urbanos de la zona, tanto ibéricos como romanos, se compense con unas densas orlas de asentamientos rurales en su entorno inmediato. La población total del territorio alcanzaría escalas equiparables a las de otras zonas de nuclearización más intensa. Sin duda estos asentamientos rurales siguen siendo los grandes desconocidos de la realidad arqueológica contestana y requerirían concentrar sobre ellos el foco de atención en un futuro inmediato. A pesar de los avances que han permitido identificar desde edificios singulares hasta humildes cabañas campesinas, pasando por centros de producción alfarera especializada, estamos lejos de poseer un conocimiento medianamente satisfactorio del hábitat rural y de los espacios de trabajo campesinos.

\section{Espacios de culto y Paisajes Sacros}

Muchos han sido los avances de los últimos años respecto a los sitios de culto en el área Contestana. Así sucede con santuarios como el de
La Carraposa (Játiva, Valencia) (Pérez y Borreda, 2004), cuevas-santuario como la Cova dels Pilars (Agres, Alicante) (Grau Mira y Olmos Romera, 2005) o santuarios litorales, como La Malladeta en Villajoyosa, recientemente excavado por A. Espinosa, J. Moratalla y P. Rouillard.

Esta variada tipología de espacios de culto que caracterizaría el área aguarda, no obstante, la realización de un estudio de detalle que permita abordar la configuración del paisaje sacro desde la perspectiva de la sanción ideológica de los procesos geopolíticos, sobre lo que ya se han avanzado algunas propuestas. En el estudio citado de L. Abad se señalaron los santuarios como posibles focos de articulación del poblamiento alicantino (Abad Casal, 1987), y se ha propuesto el papel de los santuarios como espacio especialmente favorecedor de los intercambios (Aranegui Gascó, 1995). Es posible que algunos de los que se ubican junto a los principales oppida hayan contribuido a reforzar su papel de capital, con el ejemplo paradigmático de La Serreta (Olcina Doménech et alii, 1998; Grau Mira, 2010). 
También se ha señalado la posible función de las cuevas-santuario de la Contestania como marcadores fronterizos y espacios liminales que sancionarían el reparto territorial (Grau Mira y Olmos Romera, 2005; Grau Mira, 2010). Esta función se asemejaría a los procesos de sanción sacra de los territorios que encontramos en otros ámbitos de Iberia y del Mediterráneo. En La Alta Andalucía se ha propuesto el papel de los santuarios como hitos singulares de delimitación fronteriza (Ruiz y Molinos, 2008, 61-62), de forma similar a como ya propusieron los trabajos clásicos de De Polignac (1984) para el mundo griego, o Edlund (1987) para el mundo etrusco. Esas semejanzas, y también las diferencias, permiten atisbar vías para futuros análisis de la configuración del espacio sagrado entre las sociedades ibéricas de la zona.

\section{Paisajes de la Romanización}

La romanización supuso una importante transformación de los polos de poblamiento y la reestructuración de los territorios ibéricos (Bendala Galán et alii, 1987). Como consecuencia de estos cambios, el diseño territorial quedó fijado a partir de una serie de ciudades litorales o vinculadas a las nuevas vías de comunicación. En torno a estos ejes de poblamiento han gravitado los estudios territoriales y en la actualidad hay un buen conocimiento de las ciudades romanas de tierras alicantinas y sus entornos inmediatos (Abascal y Abad Casal, 2003). Sin embargo, carecemos de un conocimiento semejante de los entornos rurales alejados de las ciudades.

En esos espacios más alejados de vías y mercados existe un modelo de poblamiento con un carácter muy arraigado en las tradiciones de aprovechamiento del campo ibéricas y en fórmulas de explotación campesina (Grau Mira y Garrigòs Albert, 2008; Frías Castillejo, 2010). Todo parece indicar que los modelos de agricultura de plantación basados en los asentamientos tipo villae orientados al mercado no fueron los predominantes en los espacios periféricos, sin que ello suponga que no estuvieran explotados según otra lógica económica. Pero la cuestión está abierta y a la espera de estudios de detalle que son necesarios.

4 Un estado de la cuestión en el artículo de Lorenzo Abad en AA.VV., 2011.

\section{A la busca de Roma (L.A., A.E.)}

\section{In agro...}

Uno de estos estudios ha permitido descubrir en el entorno de Villajoyosa la villa suburbana de El Xarquet, estudiada por Amanda Marcos (Marcos González, 2010), uno de los escasos ejemplos de villas romanas completas documentadas en la Comunidad Valenciana. De $3000 \mathrm{~m}^{2}$, presenta una primera fase entre 15 a. C. y el año $1 / 10$ d.C., y una segunda hasta mediados del siglo I, con una importante reforma entre ambas. El Xarquet se abría a un tramo de calzada en dirección este-oeste que forma parte de una centuriación actualmente en estudio.

Ha podido constatarse que las calzadas que, desde la ciudad se dirigían a Lucentum y los valles de Alcoy, servían de eje respectivamente a las necrópolis de Poble Nou y Casetes, que perduran desde la época orientalizante hasta la tardorromana, mostrando que la disposición del paisaje funerario ibérico no difería mucho del romano posterior (Espinosa Ruiz, Ruiz Alcalde y Marcos González, 2005; Marcos González y Ruiz Alcalde, 2005; García Gandía, 2009). Se han excavado varios cientos de tumbas, en proceso de estudio y de publicación. Entre ellas destacan el sector orientalizante de Casetes, los sectores del Ibérico Final y altoimperial del sector Creueta de esta misma necrópolis, y los sectores del Ibérico Antiguo, Pleno y Final en la de Poble Nou. Además, dispersas, no faltan tumbas de inhumación bajoimperiales.

Dentro del proyecto Villajoyosa Romana, desarrollado con Lorenzo Abad, Sonia Gutiérrez e Ignacio Grau, se ha excavado -está aún por concluir - el entorno de la Torre de Sant Josep, uno de los mejores monumentos funerarios hispanos, rescatado del olvido en 1984 por Lorenzo Abad y Manuel Bendala ${ }^{4}$. La demolición del inmueble adosado a la torre y el paso de la misma junto con su entorno a propiedad municipal han propiciado que las administraciones local y autonómica retomen el proyecto de restauración y musealización de este importante monumento (Fig. 4).

Se ha iniciado el estudio de la villa rural tardorromana de Xauxelles (o Torre-la Cruz), declarada bien de interés cultural, para su próxima prospección y excavación. Uno de los objetivos 


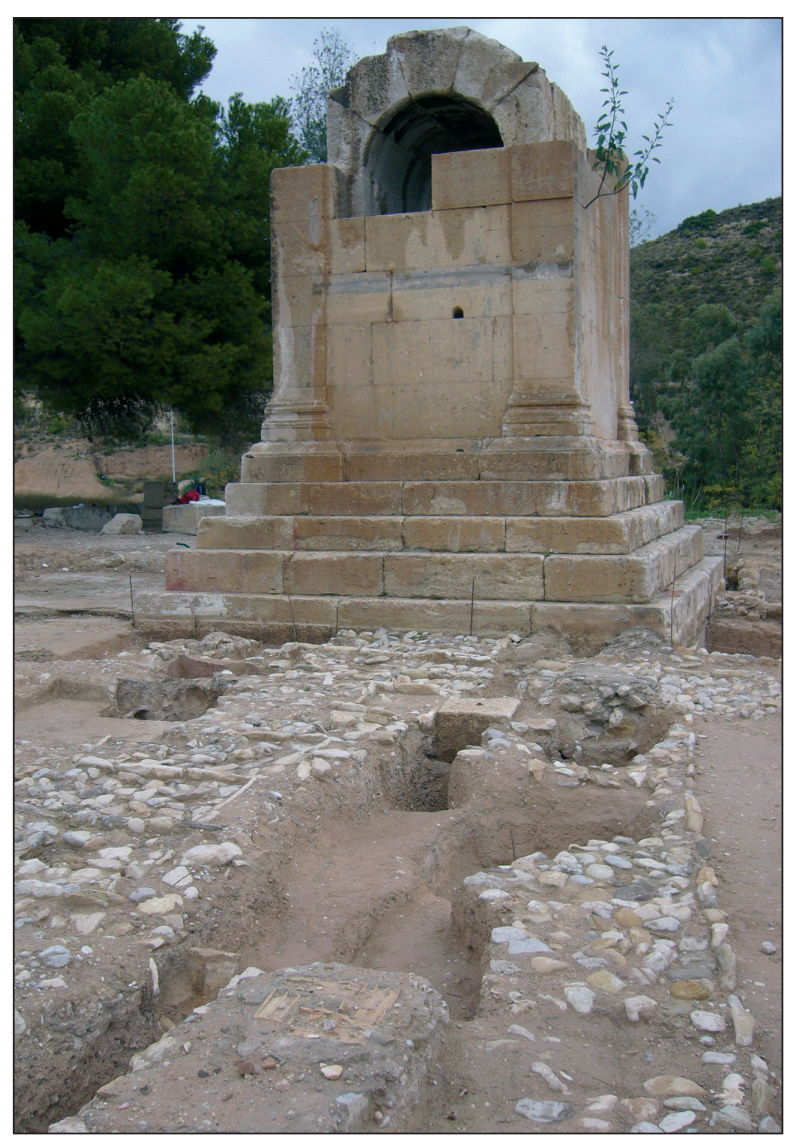

Figura 4. La Torre de Sant Josep de Villajoyosa. Estado actual (2011)

es contrastar arqueológicamente la controversia teórica entre quienes defienden una fecha tardía para las tallas murales sobre mortero (con paralelos del siglo VIII en Próximo Oriente, como el yacimiento palestino de Jirbat al Majfar) (Caballero Zoreda, 2000) y quienes consideran que las tallas son contemporáneas a los mosaicos de finales del siglo III que decoran los suelos de estos baños privados, opinión que comparte el equipo director del proyecto Villajoyosa Romana (cf. Gutiérrez Lloret y Sarabia Bautista, 2007). Excavaciones practicadas durante el seguimiento de la instalación de un gaseoducto en la parte baja al este del cerro de Xauxelles, han localizado una fase altoimperial, de tipo residencial, que confirma la gran extensión del yacimiento y sus enormes posibilidades e interés científicos.

5 Agradecemos esta información inédita a Silvia Mancha.

6 Aunque la bibliografía generada en tan poco tiempo es muy amplia, véase Alföldy 2003, 41-45, que recoge toda la anterior, Abad 2010 y Olcina, 2011.

7 La primera propuesta de lectura y restitución (Abad, 1996) modificada recientemente por Alföldy (2007), quedaría como sigue: Imperator - Caesar . Augustus . Pontifex .
Seguramente lo más espectacular en este proceso ha sido la aparición en el año 1996 de la placa de bronce conocida como Tabula de Ilici, descubierta por desgracia en niveles superficiales y revueltos en el yacimiento de La Alcudia de Elche. Ofrece una magnífica instantánea del momento de la fundación colonial, que entre todas las posibles hipótesis, parece podemos datar en torno al año 27 o 26 antes de nuestra era, y atestigua el reparto de 130 yugadas de terreno entre diez individuos que proceden de ciudades de la Bética, el sur de Italia, el norte de África o las islas Baleares ${ }^{6}$.

\section{Et in urbe...}

Los trabajos de campo realizados en los últimos años en El Tolmo de Minateda, La Alcudia y Villajoyosa han permitido mejorar el conocimiento de una de las ciudades romanas (Ilici, La Alcudia de Elche) y sobre todo sacar de la inexistencia (Ilunum, Tolmo de Minateda) o del anonimato (Alone, Villajoyosa) a otras dos.

El Tolmo de Minateda fue el primero; desde el año 1988 un equipo de la Universidad de Alicante y del Museo de Albacete viene poniendo al descubierto un importante yacimiento cuya adscripción cronológica y cultural se ha ido labrando de campaña en campaña. El detonante fue la aparición de parte de una inscripción monumental, en un derrumbe arquitectónico que pronto estuvo claro no podía ser su emplazamiento original. Después de varias campañas pudimos recomponer la secuencia del proceso. Una estructura maciza, ataludada, de mampostería con alzado de adobe, que debió tejerse y destejerse repetidamente a lo largo de los siglos, se reviste en el año 9 antes de nuestra era con un muro de opus quadratum que le confiere prestancia. La fecha viene determinada por la inscripción monumental que campeaba sobre la puerta de este muro ${ }^{7}$. Sus piezas habían sido reaprovechadas en la última obra: un baluarte construido en época visigoda en forma de L que adelantaba y reforzaba el plano

Maximus $\cdot$ Tribunicia / Potestate $\cdot X V \cdot \operatorname{Cos} \cdot X I \cdot I m p \cdot X I I I$ $\cdot$ murum $\cdot$ et $\cdot$ portam $\cdot$ dedit / Ilunitanis $\cdot o b \cdot$ insignem . fidem $\cdot$ eorum $/ L \cdot$ Domitius $\cdot$ Ahenobarbus $\cdot$ leg $\cdot$ eius $\cdot$ pro - praetore $\cdot$ dedicavit / Nero $\cdot$ Claudio $\cdot$ Druso $\cdot T \cdot$ Quinctio Crispino - Cos. Esta interpretación recoge y afianza la hipótesis de que la obra construida se trate de un muro y una puerta y que los destinatarios sean los ilunitanos. 
defensivo. En su obra se habían reaprovechado numerosos materiales: fragmentos de escultura y sillares decorados, fustes de columna y otros elementos arquitectónicos, y sobre todo epígrafes, tanto en el interior del relleno como formando parte del propio muro. Su estudio nos ha permitido conocer el proceso evolutivo de las estructuras defensivas (Gutiérrez Lloret y Abad Casal, 2002), localizar un municipio perdido (Ilunum, citado por Ptolomeo, II, 6, 60) y ampliar considerablemente el elenco de nombres romanos de esta zona del conventus carthaginiensis (Abad Casal, 1996) (Fig. 5).

En torno a este hallazgo principal se produjeron otros complementarios, aunque no menos importantes: una necrópolis de época tardorrepublicana, en la que se mezclan materiales y estructuras de tradición ibéricos con materiales y nombres romanos (Sanz Gamo, 1997), y un conjunto de vías que comparten la plataforma noroccidental de acceso, que muestra lo intenso del tráfico rodado y las vicisitudes por las que este camino pasó. La última de ellas, y no menos importante, el derrumbe de la esquina de la estructura visigoda, caída a plomo, muy probablemente como con- secuencia de un movimiento sísmico, que dejó inservible la última parte del camino, que ya nunca más se volvió a utilizar.

Este derrumbe, que sella e inutiliza el antiguo camino, resulta una metáfora del devenir del cerro. El fulgurante comienzo romano se fue atemperando con el paso del tiempo; poco a poco se vio que las estructuras que iban surgiendo tenían poco de romanas, que lo romano aparecía en los recovecos de la roca no arrasada por los visigodos o como elemento residual en los niveles visigodos y sobre todo islámicos. Lo que parecía un prometedor yacimiento romano fue languideciendo al tiempo que se iba desvelando un espectacular yacimiento altomedieval. La desilusión de algunos miembros del equipo se compensaba con el alborozo de otros. Hoy el Tolmo de Minateda es uno de los Parques Arqueológicos de la Junta de Comunidades de Castilla-La Mancha y un referente para el estudio de este periodo en el Mediterráneo occidental (Abad Casal, Gutiérrez Lloret, Gamo Parras y Cánovas Guillén, 2011).

La Alcudia es el segundo de los yacimientos, vinculado a la Universidad de Alicante tras la creación de la Fundación Universitaria de

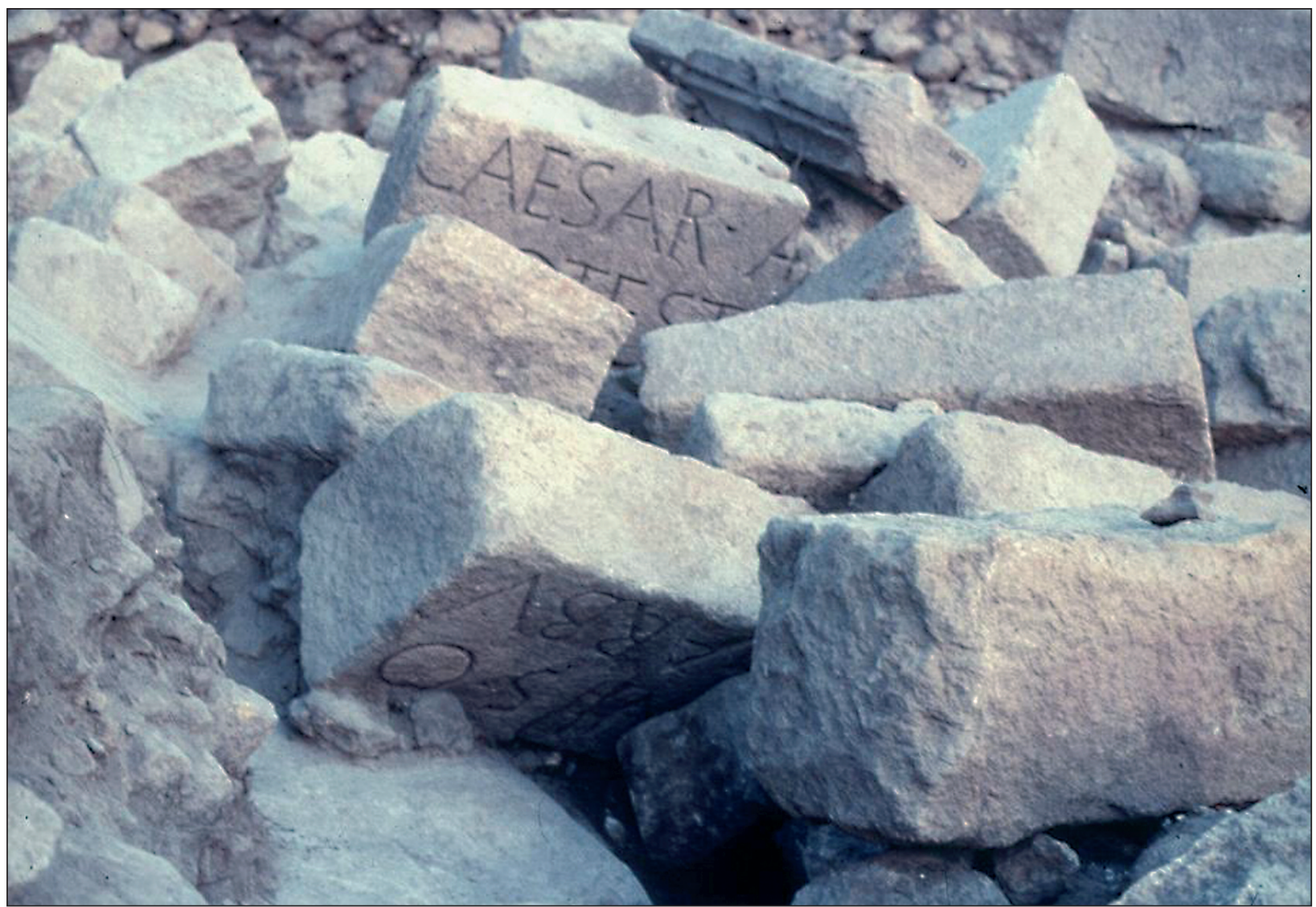

Figura 5. Derrumbe de sillares augusteos reaprovechados en el muro del baluarte visigodo de El Tolmo de Minateda 
Investigación Arqueológica La Alcudia de Elche. Ésta surgió en el año 1996 como consecuencia de un acuerdo entre la Universidad de Alicante, el Ayuntamiento de Elche y la familia propietaria del yacimiento, aunque la vinculación efectiva no se produjera hasta varios años después ${ }^{8}$. El yacimiento y la colección museográfica quedaban bajo la tutela de la Fundación. Pero lo que la Fundación heredaba era un edificio que hacía agua; no sólo en su estructura física, sino también en su organización. Uno de sus grandes activos resultaba ser también uno de sus principales pasivos: una importante colección arqueológica, alojada en condiciones precarias en medio del campo de Elche, cuyo saneamiento obligó a drenar los recursos que hubieran podido destinarse al propio yacimiento. Por suerte eran años prósperos y la incorporación a la Fundación de la Diputación Provincial de Alicante y -de una manera más testimonial- la Generalitat Valenciana, permitió construir un Centro de Interpretación - en realidad un nuevo museo, aunque se mantuviera el nombre original previsto - que ha permitido albergar la parte principal de la colección en condiciones dignas.
Actualmente está en marcha la remodelación del antiguo museo, renovando las instalaciones expositivas, los laboratorios y los despachos. Cuando concluya este periodo, la infraestructura de $\mathrm{La}$ Alcudia, imprescindible para plantear un trabajo arqueológico de alcance, estará a punto.

Durante la construcción del Centro de Interpretación, gracias a un convenio con la Fundación Marq, se excavó un largo lienzo de una muralla de mampostería y adobe que parece haber estado vinculada a la fundación colonial, aunque su datación concreta esté aún por determinar. Esta muralla tuvo una vida corta; poco más de cien años después de su construcción estaba ya parcialmente desmontada; sobre ella se alzó la plataforma de un gran espacio termal y se acumularon vertederos de material de construcción, que permitieron ganar terreno por el exterior (Abad Casal, 2010) (Fig. 6).

En estos momentos está en proceso una excavación al norte del edificio termal descubierto por Pedro Ibarra a finales del siglo XIX, vestigios de las cuales, aunque muy alterados, han ido apare-

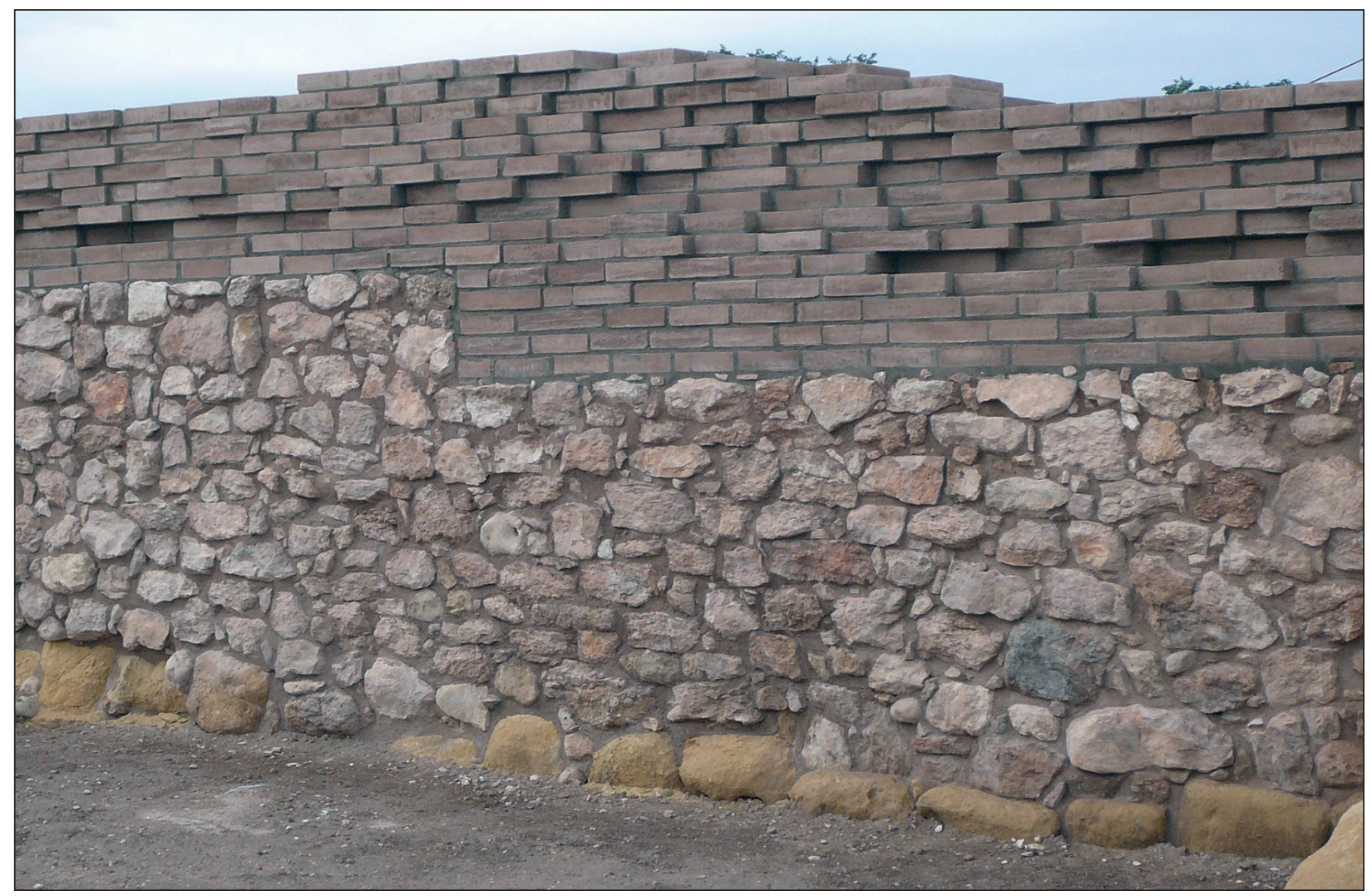

Figura 6. Muralla restaurada de La Alcudia de Elche

8 Una puesta al día de la arqueología de Ilici en ese momento puede verse en Abad Casal, L. y Hernández Pérez, M. (eds):
Iberia, Hispania, Spania. Una mirada desde Ilici. Catálogo de la Exposición. Alicante, 2004. 
ciendo. El yacimiento contaba con dos edificios termales, uno al este y otro al oeste de la loma que tradicionalmente se ha identificado con $\mathrm{La}$ Alcudia; aunque hoy sabemos que la ciudad romana se extendía por su entorno, con seguridad hacia el este y el norte, y posiblemente también hacia el oeste, en tanto que el antiguo asentamiento ibérico quedó convertido en la zona noble y residencial (Ramos Molina y Tendero Porras, 2000, 205-210; Abad Casal, 2010a).

El proyecto de Villajoyosa es el que más novedades científicas ha aportado a la Arqueología romana. Una serie de actuaciones urbanísticas y normativas permitieron la aprobación en 1992 de la Normativa Municipal sobre Remoción de Terrenos en Zonas Arqueológicas, que venía a suplir en el ámbito local la falta de una legislación comunitaria más concreta que la estatal de 1985. Esta normativa permitió que, en pleno desarrollo urbanístico de la ciudad, algunos yacimientos de primer orden como la necrópolis de Poble Nou (s. VI a.C.-s. IV d. C.) no desaparecieran por completo; el famoso collar orientalizante, una de las joyas fenicio-púnicas más destacadas de la Península Ibérica, aparecida aquí en 1995, dio el impulso definitivo al reconocimiento del Museo Municipal. A su alrededor se ha ido aglutinando un núcleo de profesionales de la arqueología, la etnografía, la museología, la divulgación y la restauración, constituyendo uno de los equipos interdisciplinares más completos del panorama valenciano. El permanente conflicto entre arqueología y urbanismo ha quedado minimizado gracias a la interlocución de la Sección Municipal de Arqueología, Etnografía y Museos con los propietarios de los terrenos y al apoyo que la Sección brinda en todo momento a las empresas privadas de arqueología.

Un hallazgo muy interesante ha sido la fossa fastigata de un campamento militar de las guerras sertorianas descubierta por A. Espinosa en el solar de la calle Colón, 15-17 en 1995, de la que posteriormente se han excavado dos sectores más (2006 en la calle Colón esquina con Pizarro y 2007 en la calle Colón 24-28), bajo la dirección de Diego Ruiz y Amanda Marcos. Supone el primer yacimiento de este tipo hallado en la Comunidad Valenciana (Espinosa Ruiz et alii, 2006) y un paso adelante en la revalorización de este periodo. Sobre el rastreo arqueológico de la presencia sertoriana en las costas valencianas se encuentra dirigiendo Feliciana Sala un proyecto de investigación que está aún en sus inicios pero que ofrece ya prometedores resultados (HAR2009-11334: "Desarrollo de las guerras civiles romanas y la transformación del mundo indígena en el Sureste de Hispania").

Lo más destacado ha sido el hallazgo del núcleo urbano de la ciudad romana de Villajoyosa por Diego Ruiz y Amanda Marcos (Ruiz Alcalde, 2010). Los exhaustivos sondeos mecánicos en la partida de Torres en 2007 descartaron por completo la opción más extendida, la de que estuviera ubicada en las inmediaciones de la torre de Sant Josep, en tanto que la excavación de unas termas monumentales en la calle Canalejas de Villajoyosa confirmaba que se encontraba en el núcleo de la ciudad actual (Fig. 7). Hoy queda claro que la ciudad indígena se estableció, probablemente ya en el Bronce Final, sobre el cerro del casco antiguo, el mismo emplazamiento que ocupará la ciudad romana, cuyos edificios oficiales se disponen en torno a un nuevo foro a extramuros del viejo recinto ibérico.

Ese foro estaría en la actual plaza de la Generalitat, y a su alrededor, como consecuencia de la obtención de la categoría de municipium latinum con el Edicto de Vespasiano, hacia $74 \mathrm{~d}$. C., se construirían, entre 85 y 110 , según el reciente estudio de Diego Ruiz, las termas monumentales de Canalejas; también el macellum de cuya restauración en el siglo II nos habla una inscripción conmemorativa; la curia y uno o más templos, uno de los cuales debía estar dedicado al culto imperial (Espinosa Ruiz, 2006).

La excavación del santuario del Tossal de la Malladeta dentro del Proyecto Villajoyosa Ibérica por un equipo hispano-francés bajo la dirección de Pierre Rouillard, Jesús Moratalla y el equipo técnico del Museo Municipal, entre 2005 y 2009, ha puesto de relieve además un lugar sacro, dedicado a la diosa-madre, que ya está ocupado en el siglo IV a. C. y que experimenta una gran reforma hacia el año 100 a. C. Igualmente interesante es la constatación de que este lugar se abandona en el último cuarto del siglo I, coincidiendo con el desarrollo del nuevo foro municipal, al que se trasladan las funciones religiosas del viejo santuario?.

9 Remitimos al artículo de los directores en AA.VV 2011. 


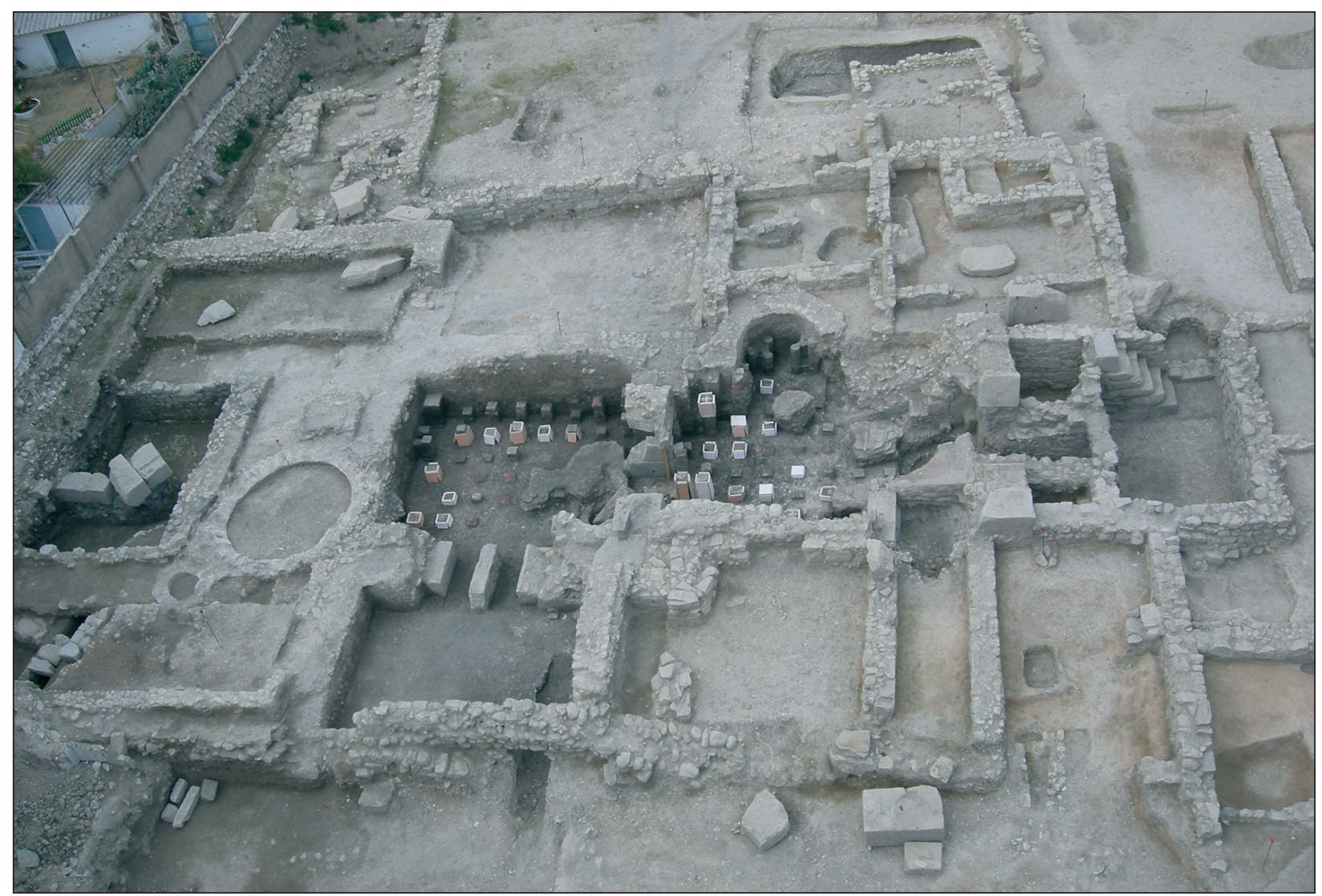

Figura 7. Termas romanas de Villajoyosa

Desde Villajoyosa se desarrolló también entre 1989 y 1995 la carta arqueológica subacuática de la comarca, bajo la dirección de Antonio Espinosa, Fernando Sáez y Rocío Castillo, con el patrocinio de la Generalitat Valenciana y, en la primera campaña, del Ministerio de Cultura. Se descubrieron y prospectaron diferentes yacimientos, entre los que cabe destacar los fondeaderos de la Fonda, frente a la playa de Villajoyosa, y de la Olla, en Altea, asociados a buenos fondos para echar el ancla y buenas playas para el varado, y cerca de buenas aguadas en los ríos de la Vila y Algar, respectivamente. La Fonda es uno de los principales puertos históricos valencianos por su constante actividad, en relación con la navegación desde época orientalizante hasta 1920 (cf.

10 El proyecto ANSER Anciennes Routes Maritimes Méditerranéennes de la Unión Europea en la Comunidad Valenciana (Castillo, coord. 2004) se desarrolló en 2003 y 2004 en las costas de Villajoyosa. Se realizó una primera actuación sobre el pecio Bou-Ferrer, comunicado por sus descubridores al Museo municipal en 2000 gracias a una acción de difusión científica del proyecto Carta Arqueológica Subacuática de la Marina Baja en el Club Náutico de Villajoyosa. En colaboración con la Universidad de Barcelona, se llevó a cabo un sondeo interdisciplinar en
Espinosa Ruiz, Sáez y Castillo, 2006, con toda la bibliografía anterior). Dentro del proyecto ANSER se excavó el pecio Bou-Ferrer, uno de los más relevantes en curso de excavación de todo el Mediterráneo $^{10}$.

\section{De Hispania a al-Andalus (S.G.)}

La arqueología de la transición de Hispania a Al-Andalus es una de las investigaciones más innovadoras que se ha abordado desde el Área de Arqueología en estos últimos años; es consecuencia de la perspectiva plural y diacrónica con que enfocamos el nacimiento y la consolidación de la arqueología en nuestra universidad, atenta a todas las épocas y capaz de reconocer un terreno meto-

la pradera de Posidonia oceánica que, combinado con análisis C14 de los rizomas, ha ofrecido interesantes resultados que ayudan a comprender la dinámica de los fondeaderos antiguos en el Mediterráneo (Mateo et alii, 2004). Desde 2006 se ha hecho cargo de las investigaciones subacuáticas la Generalitat Valenciana, bajo la dirección de Enriqueta Vento, Carlos de Juan y Franca Cibecchini, con el apoyo del Museo de Villajoyosa. Un estado de la cuestión en el artículo de los directores en AA.VV., 2011. 
dológico unificante para toda su práctica, con independencia del periodo, tema, enfoque o estrategia investigadora elegidos, incluyendo el ejercicio profesional.

En el origen se sitúan dos estrategias de investigación de distinta naturaleza, que se remontan a finales de los años ochenta. La primera, un estudio sobre la Alta Edad Media en el espacio del sudeste de la Península Ibérica conocido como la Cora de Tudmir, tanto a partir de las fuentes escritas como de las materiales que la metodología arqueológica proporcionaba. Se pudo realizar la primera clasificación cronomorfológica regional de las producciones visigodas y emirales, el reconocimiento de ciertos patrones de asentamiento y su caracterización étnica y social. El estudio arqueológico del ambiente urbano altomedieval permitió la identificación material de las ciudades del famoso Pacto de Teodomiro, más allá de cualquier especulación derivada de las eventuales lecturas de los topónimos transmitidos por las fuentes escritas (Gutiérrez Lloret, 1996).

La segunda, la posibilidad de aplicar estos principios en un proyecto arqueológico de excavación sistemática en el Tolmo de Minateda, al que ya nos hemos referido y cuya vertiente tardía se ha revelado especialmente fructífera. Las fases altomedievales del asentamiento se revelaron espectaculares, tanto por la magnitud y extensión de los vestigios conservados como por su interés histórico al tratarse de la célebre Madinat Iyyuh mencionada en el Pacto de Teodomiro del año 713, probable trasunto de la visigoda ciuitas de Eio, sede episcopal creada por los reyes visigodos en los umbrales del siglo VII. (Abad Casal et alii, 2000, Gutiérrez Lloret, 2000), con una secuencia ininterrumpida de ocupación entre los siglos VI y IX. Resulta equiparable a otros importantes yacimientos urbanos como Valencia, Mérida, Córdoba o Cartagena, sólo que a diferencia de éstos su condición de despoblado ha contribuido a fosilizar la trama urbana alto medieval en su estado prístino, de forma únicamente comparable a los casos de Recópolis, Pechina, Madinat al-Zahra o la recientemente exhumada Vega Baja toledana.

Las degradadas ciudades de origen romano o visigodo que los conquistadores musulmanes encontraron el 711, en general no se abandonaron de forma brusca, aunque muchas no lograron sobrevivir al siglo VIII. En el caso del Tolmo, uno de los logros arqueológicos más importantes ha sido precisamente el reconocimiento material del siglo VIII, es decir, de las producciones que lo caracterizan, gracias a la obtención de secuencias estratigráficas con continuidad entre los siglos VII y IX y a su contrastación con dataciones numismáticas o radiocarbónicas. Gracias a ello se ha podido documentar la transformación de un área monumental, pública y religiosa del siglo VII en un barrio residencial privado en el siglo IX (Fig. 8) (Gutiérrez Lloret, 2008a, Gutiérrez Lloret y Cañavate Castejón, 2010, Amorós Asensi y

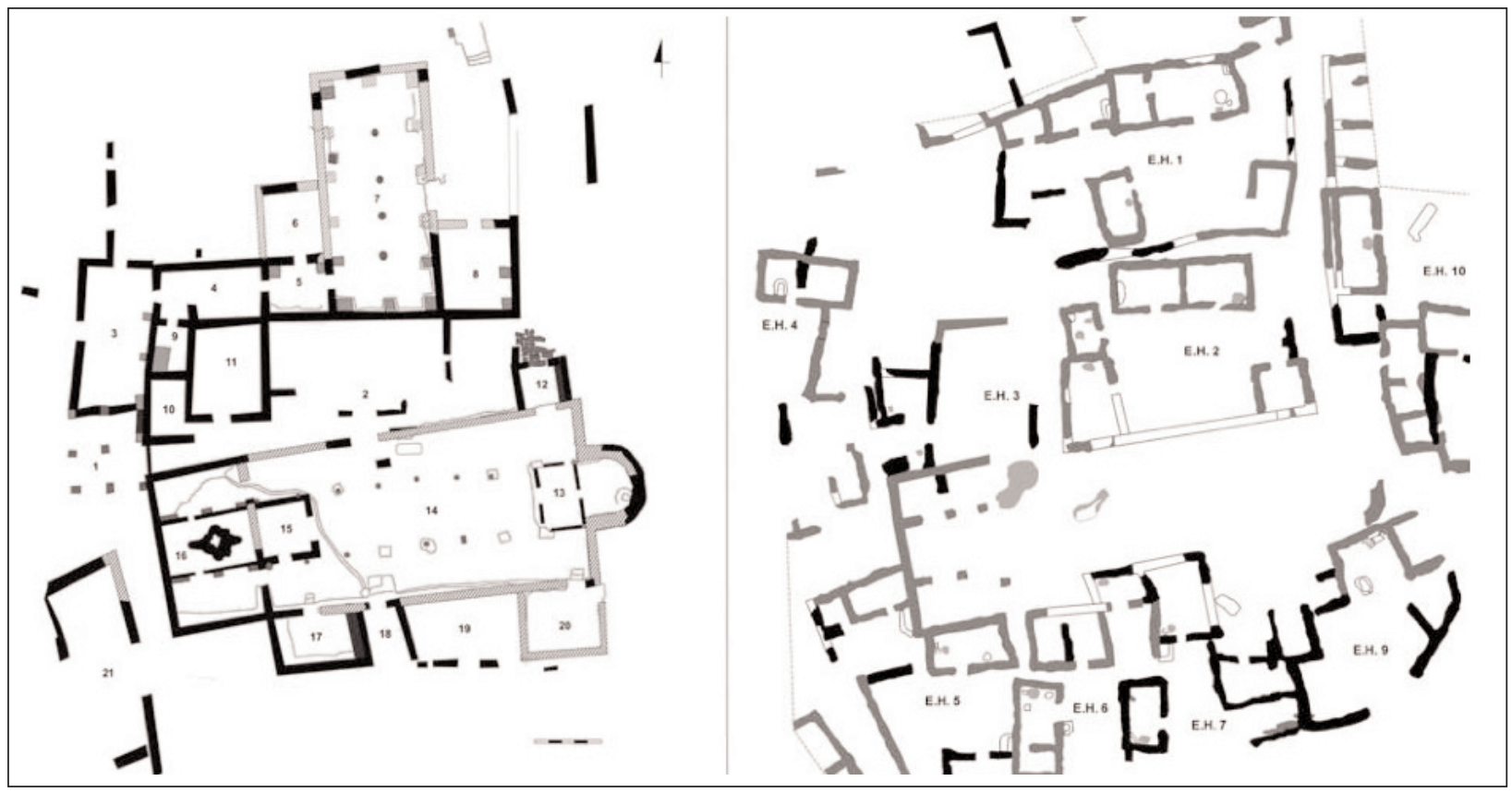

Figura 8. Complejo episcopal visigodo (S.VII) de El Tolmo de Minateda y su transformación en arrabal islámico (S. IX) 
Cañavate Castejón, 2010, Cañavate et alii, 2009). En el caso de Ilici (La Alcudia, Elche), la creación de la Fundación ha permitido replantear la agenda investigadora, reestudiando y datando correctamente los restos tardoantiguos, y explorando su eventual continuidad en época emiral, al menos durante el siglo VIII (Gutiérrez Lloret, 2004; Lorenzo San Román, 2006).

No obstante, la constatación arqueológica de la continuidad de ocupación de ciertos núcleos urbanos de Tudmir durante los siglos VIII e incluso IX, no significa la continuidad de la vida urbana en el sentido clásico. Las ciudades de Hispania fueron la base inicial de un nuevo modelo de control del territorio, pero pronto fueron suplantadas por un impulso urbano distinto, plenamente islámico. Las ciudades de al-Andalus se consolidaron entre los siglos IX y X, con apariencia de continuidad sobre los degradados centros visigodos (como Valencia, Córdoba o Zaragoza), enfatizando la ruptura en nuevos emplazamientos elegidos al margen del poder (Bayyana / Pechina) o fundados directamente por él, como Murcia o Badajoz durante el Emirato y Almería o Madinat al-Zahra ya en el Califato.

En el sudeste ha comenzado a identificarse una nueva modalidad de asentamiento, propia de la época visigoda avanzada y coetánea en su proliferación a la reviviscencia urbana del Tolmo de Minateda como cabeza administrativa y episcopal de la región. Se trata de un conjunto de asentamientos rústicos de pequeñas dimensiones, con sus correspondientes necrópolis, que ocupan colinas en zonas muy fértiles, cerca de arroyos o manantiales, con características edilicias comparables a las de la ciudad del Tolmo (muros de mampostería con grandes adarajas) y materiales (cerámica y toréutica) correspondientes a un horizonte plenamente visigodo, fechable en el siglo VII. En algunos casos - Loma Eugenia y Loma de los Coches-Torre Uchea - se documentan enterramientos junto a las zonas de hábitat, lo que supondría la voluntad de fijación a la tierra en ciclos plurigeneracionales y por tanto la naturaleza estable de estas aldeas, que no parecen depender de un centro religioso inmediato para atender las prácticas funerarias, sino más bien de la ciudad del Tolmo (Gutiérrez Lloret y Grau Mira, 2012).

\section{El reconocimiento arqueológico de la islamización}

Los distintos aspectos materiales estudiados en el marco del proyecto de investigación sobre el
Tolmo de Minateda han servido también para plantear desde diversas perspectivas el problema de la islamización y su reconocimiento arqueológico, a partir de indicadores sociales, culturales y cronológicos (Gutiérrez Lloret, 2011a, 2011b).

En primer lugar, el modelo de unidad doméstica constatado en el Tolmo durante el Emirato no se ajusta al esquema monocelular clásico, como se venía suponiendo, sino que ilustra el proceso de transición hacia un modelo estructural de mayor complejidad, basado en la agregación -en ocasiones sucesiva- de varias estancias rectangulares en torno a un espacio abierto de grandes dimensiones, que constituye el elemento vertebrador de la casa (Gutiérrez Lloret, 2008a). Quizás lo más relevante sea constatar que dicho proceso no sólo puede evidenciar la especialización funcional de los diversos ambientes (residencia y reposo, transformación de alimentos, almacenaje, actividad ganadera y artesanal, etc.) sino también una relativa segmentación social, al reconocerse más de un "hogar" dentro de cada casa. Desde esta perspectiva, cada una de las estancias con área de combustión podría interpretarse como la "vivienda" concreta de otras tantas unidades familiares reducidas dentro del grupo familiar extenso al que pertenece la unidad doméstica compleja en su conjunto y que puede compartir ciertos espacios comunes (Gutiérrez Lloret y Cañavate Castejón, 2010).

La difusión del Islam y de la lengua árabe son, sin duda, dos expresiones ideológicas fundamentales de la formación social islámica. La primera se refleja en la aparición de una edilicia religiosa específica y su relación con los antiguos edificios de culto, transformados en ciertas ocasiones en mezquitas, a más de la adopción del nuevo ritual funerario; la segunda se aprecia en el ritmo de adopción de la nueva lengua a través de la escritura en todos sus soportes. Durante los siglos VIII y IX se levantan las primeras mezquitas, que en ocasiones coexisten con las viejas iglesias cristianas y en otras las suplantan. La construcción del Ribat de Guardamar a finales del siglo IX junto a la desembocadura del río Segura (Azuar, 2004) ilustra la difusión del Islam en el medio rural, mientras los escritos espontáneos que dejaron los visitantes en sus paredes o que escribieron los alfareros en sus cerámicas en producciones del siglo IX, denotan a más de un significativo grado de alfabetización, que el árabe ya era la lengua de al-Andalus, aunque la epigrafía funeraria y conmemorativa no se date antes del siglo $\mathrm{X}$. La islamización religiosa y 
la arabización linguiística se reconocen tempranamente desde una perspectiva material (Gutiérrez Lloret, 2006, 2011a)

La contextualización estratigráfica de ciertos elementos como los ajimeces - piezas de ventana geminadas o simples talladas en un bloque-, capiteles, canceles, etc, han permitido localizar talleres y centros de producción; el estudio de las técnicas constructivas o del reempleo de materiales antiguos evidencia la organización de los ciclos productivos y abre puertas para superar la aproximación estilística hasta ahora tradicional (Sarabia Bautista, 2003; Gutiérrez Lloret y Sarabia Bautista, 2007).

La obtención de secuencias fiables ha permitido reconocer y aislar horizontes productivos: el horizonte I, que consideramos visigodo, fechable entre la segunda mitad del siglo VII y quizá el primer cuarto del siglo VIII; el horizonte II, que corresponde a la parte central y final del siglo VIII, es de cronología emiral temprana aunque sus producciones suelen estar morfológicamente más próximas a las visigodas; y el horizonte III, que se inscribe claramente en el siglo IX, acorde con los repertorios emirales hasta ahora documentados en Tudmir y en algunos lugares de Andalucía oriental (Gutiérrez Lloret et alii, 2003)

En el siglo VII se simplifican los procesos productivos, desaparece el comercio y se generalizan formas de distribución y consumo puramente locales. Las estandarizadas vajillas romanas son sustituidas por sencillos ajuares locales en los que reaparece incluso la cerámica modelada a mano. Únicamente sobreviven formas sencillas y prácticas como las ollas y cazuelas que parecen inspirarse en la cerámica de cocina africana o las botellas y cuencos herederos de las formas romanas de terra sigillata hispanica tardía. Pero esta aparente continuidad pronto se ve matizada por la incorporación en el siglo VIII de formas y decoraciones ajenas a la tradición local, como el jarro de hombro carenado, el tannur para cocer el pan o el arcaduz de noria, que representan tradiciones culturales distintas y, lo que es más importante, evidencian la introducción de nuevos alimentos y prácticas agrícolas vinculadas con el regadío.

\section{EL ANÁlisis ARQUEOLÓGICO DE LOS REGISTROS NUMISMÁTICOS (C.D.)}

El análisis arqueológico de los materiales numismáticos, más allá de su uso tradicional como indicador cronológico y elemento de data- ción, entra de lleno en alguna de las problemáticas históricas de dicho periodo, como son el proceso de adopción de los modelos culturales islámicos por parte de la sociedad hispano-visigoda, la adscripción de algunos contextos cerámicos o la determinación de la entidad de diferentes enclaves poblacionales. Por otra parte, la contextualización estratigráfica de los registros monetales y su vinculación con otros restos arqueológicos permite conocer el tiempo que una moneda estuvo en circulación, su momento y lugar de uso, y evidencia el riesgo de datar los sitios arqueológicos a partir de la fecha de emisión de la moneda, lo que puede llevar a errores importantes. Esta información, que sólo es posible obtener a partir de la información estratigráfica, ha sido fundamental en el estudio de determinados procesos históricos relacionados con la historia económica en general y con la moneda en particular, como es el caso de los fenómenos de pervivencia de un determinado numerario (Domenech Belda, 2008, 2010).

El final del periodo visigodo se sitúa para el área del sureste peninsular en el año 713, con la firma de un pacto entre el representante del reino de Toledo, Teodomiro, y el caudillo islámico 'Abd al-'Aziz ibn Musa. El pacto prolongaba el gobierno de Teodomiro en este territorio a cambio de un tributo, pero la documentación arqueológica muestra indicios de un proceso de islamización que comienza en época temprana y que avanzará rápidamente hasta su culminación en época califal. En este proceso, la moneda se convierte en un indicador importante junto a la cerámica, que en el siglo VIII resulta de difícil reconocimiento dado sus rasgos visigotizantes, como se ha comprobado en El Tolmo de Minateda en Hellín (Albacete).

En este mismo yacimiento, los trabajos arqueológicos han sacado a la luz un importante registro numismático procedente en gran parte de estratos arqueológicos fiables, lo que ha permitido realizar un estudio contextualizado de estos materiales. La presencia de las primeras monedas islámicas sitúa los estratos arqueológicos en cuestión en un momento posterior a la llegada de los musulmanes, toda vez que constata el mantenimiento de antiguas monedas romanas. Del mismo modo, ha sido posible estudiar el proceso de islamización a través de la moneda, que se produjo de manera gradual y progresiva, con un siglo VIII donde solo circula moneda de cobre, fundamentalmente romana con algunos feluses de adscrip- 
ción islámica, cuyo número irá aumentando a la vez que aparece la moneda de plata islámica y van desapareciendo los viejos cobres tardorromanos.

La relación de los registros numismáticos con la cerámica, otro gran indicador tanto de la cronología como de los fenómenos económicos, ha abierto una línea de interés creciente y de alto potencial cronológico. Y nos referimos a los registros cerámicos asociados estratigráficamente a piezas monetarias. Ellos nos aportarán, en muchos casos, la fecha del momento de uso de las monedas, mientras que en otros, éstas pueden contribuir a matizarlos cronológicamente, como sucede en el caso de las formas más tardías de la sigillata africana D, cuya datación se ha prolongado hasta finales del siglo VII, a partir de los registros monetales de Crypta Balbi en Roma ${ }^{11}$. La moneda puede también ayudar a determinar adscripciones difíciles de contextos cerámicos, como se ha evidenciado en El Tolmo de Minateda, donde la contextualización de la moneda ha permitido reconocer con certeza cronológica los repertorios cerámicos del siglo VIII ${ }^{12}$.

En este discurso histórico, la moneda puede también relacionarse con el poblamiento y convertirse en un indicador de la entidad de los distintos centros poblacionales. La presencia o no de moneda, la cantidad y entidad de los hallazgos, el valor adquisitivo de las especies monetarias localizadas o la procedencia de las piezas, se convierten en importantes indicadores de la entidad de un determinado asentamiento y del papel jugado en la estructura y organización territorial. La vinculación de los hallazgos de trientes visigodos con los centros episcopales propuesta por algunos autores, aunque aún por demostrar, estaría en esa línea de investigación. (Fig. 9).

11 El análisis de los registros monetarios de Cryta Balbi en Roma realizados por A. Rovelli evidencian que, en un estrato donde se localizaron varios bronces bizantinos y un sólido acuñados a nombre de Constantino IV (668-685 d.C.) además de otro sólido de su sucesor Justiniano II en su primer reinado (685-695 d.C.), y por tanto con una cronología necesariamente posterior a esas fechas, se hallaron abundantes fragmentos de las formas más tardías de la sigillata africana D (platos Hayes 105 y 109, copas Hayes 91D, 99C y 108 , etc.) datadas, tradicionalmente, a fines del siglo VI o primera mitad del VII (Rovelli, 2002, 416). La presencia de estas monedas bizantinas con fecha de acuñación de finales del siglo VII, demuestra que estas formas cerámicas aún debían estar en uso en esas fechas y obliga a matizar su datación, prolongando el periodo de uso de las mismas.

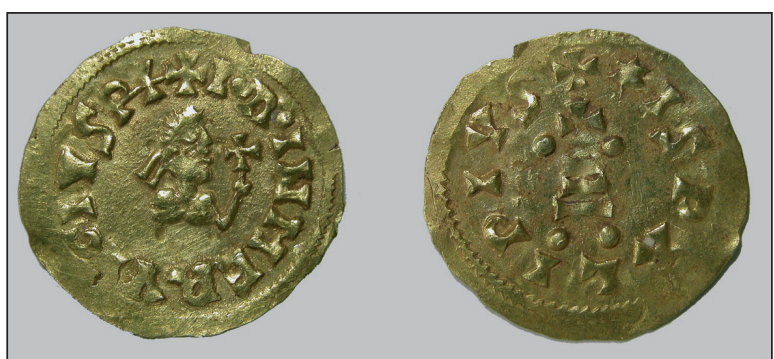

Figura 9. Triente visigodo de Ervigio, del Tolmo de Minateda.

Para el Alto Medievo, la contextualización arqueológica de los hallazgos monetarios ha permitido avanzar en alguna de las cuestiones que se vislumbraban irresolubles a partir de los estudios aislados de las monedas, entre las que cabe destacar la pervivencia del numerario tardorromano en la circulación monetaria altomedieval, fenómeno cuyas dimensiones se van conociendo de manera más precisa a partir de los contextos altomedievales o islámicos en los que aparecen. El caso más llamativo es el de los bronces bajoimperiales, fundamentalmente los acuñados en el siglo IV, cuyo mantenimiento en la circulación durante los siglos altomedievales se viene constatando desde hace tiempo. Sin embargo, solo en los últimos años el estudio contextualizado de las monedas va perfilando el alcance temporal y cuantitativo de dicho fenómeno. En este sentido los trabajos de T. Marot (1997, 2002), apoyados en evidencias arqueológicas, ponían de manifiesto cómo el numerario del siglo IV d.C. no solo subsistía y se mantenía en uso, sino que era predominante en los hallazgos fechados en el siglo VI d.C. (Marot i Salsas et alii, 2000, 509). De este modo, la arqueología empezaba a proporcionar cronologías absolutas a esta pervivencia, que ha ido ampliando el límite cronológico al sacar a la luz materiales del siglo IV d.C. localizados en ambientes de uso de las centurias VII, VIII y IX d.C.

12 En El Tolmo de Minateda los contextos cerámicos del siglo VIII han podido ser detectados sólo a partir de la secuencia estratigráfica con ayuda de la numismática. Se trata de unos conjuntos cerámicos de difícil adscripción en base a su tipología. Si la evidencia estratigráfica dejaba abierta la ubicación de estas cerámicas en un momento visigodo tardío o en una primera fase islámica, la exhumación de un felús del siglo VIII permite situarlas en un momento claramente islámico. La contextualización de la moneda permite, en este caso, reconocer los hasta entonces evanescentes repertorios cerámicos del siglo VIII (Doménech y Gutiérrez, 2006). 
El Tolmo de Minateda ha permitido cuantificar el alcance del fenómeno de esta pervivencia. El análisis numismático del horizonte emiral de este asentamiento, hecho bajo la perspectiva de estudiar no solo la moneda islámica sino todo el material monetario exhumado en los niveles islámicos del yacimiento, ha permitido obtener una visión de conjunto del circulante de dicha ciudad emiral. El planteamiento de dicho trabajo (Doménech Belda y Gutiérrez Lloret, 2006) dio como resultado, que el numerario antiguo estaba presente en unas proporciones más altas de lo que en principio cabía esperar para un enclave islámico. El hallazgo de estos cobres romanos, del siglo IV d.C. y algunos anteriores, en niveles de uso doméstico, abandono o destrucción perfectamente datados en el siglo IX demuestra que el periodo de circulación de estas especies monetarias se prolongó varias centurias. Tal cantidad de monedas romanas aparecidas en niveles asociados a la vida cotidiana de la ciudad islámica (estructuras arquitectónicas, nivelaciones constructivas, depósitos sobre pavimentos, desechos, etc.) indican que se trata de un circulante habitual y no de un numerario residual. El caso de El Tolmo y de otros enclaves altomedievales hace cada vez más improbable aceptar la circulación de cobres tardorromanos a partir de hallazgos casuales vueltos a poner en circulación que difícilmente explicarían la cantidad de monedas y la amplia difusión del fenómeno.

En este punto conviene recordar el riesgo que se corre cuando se pretende fechar a partir de las piezas de monedas sin tener en cuenta el contexto o se utilizan como único criterio de datación en yacimientos no excavados. Si este hubiera sido el caso de El Tolmo, hubiéramos afirmado que se trataba de un enclave con abundante actividad urbana durante los siglos III y IV d.C., y especialmente en esta última centuria. Nada más lejos de la realidad: a tenor de la información arqueológica, a partir del siglo II d.C. la ciudad romana sufre una involución, al tiempo que empiezan a aparecer asentamientos rústicos en el valle circundante. A partir de ese momento y hasta finales del siglo VI d.C. o inicios del VII d.C., cuando se produzca una reviviscencia urbana a partir del proyecto urbanístico visigodo, las evidencias materiales se reducen prácticamente a las numismáticas, no existiendo por el momento niveles de hábitat que indiquen un mantenimiento de la vida urbana en estas centurias (Gutiérrez Lloret y Abad Casal, 2002, 135). Por tanto, ese numerario bajoimperial mayoritariamente exhumado en el yacimiento no indica una gran actividad económica del enclave en esos momentos, sino que su contextualización en niveles visigodos e islámicos sitúa su ambiente de uso en un momento bastante alejado de su fecha de acuñación.

\section{BIBLIOGRAFÍA}

AA.VV. (2011): Villajoyosa: Arqueología y Museo. Catálogo de la exposición. Marq, Diputación de Alicante.

ABAD CASAL, L. (1984): Los orígenes de la ciudad de Alicante. Alicante, Instituto Juan Gil-Albert.

ABAD CASAL, L. (1987): "El poblamiento ibérico en la provincia de Alicante". Iberos. Actas de las Primeras Jornadas sobre el Mundo Ibérico (Jaén, 1985), 159-169. Jaén.

ABAD CASAL, L. (1996): "La epigrafía romana del Tolmo de Minateda (Hellín, Albacete) y un nuevo municipio romano del Conventus Carthaginiensis", AEspA., 69, 77-108.

ABAD CASAL, L. (2006): "The juridical promotion of oppida of the southeast of the Iberian peninsula: the cases of Ilici and Ilunum", en L. Abad, S. Keay y S.F. Ramallo (eds.): Early Roman Towns in Hispania Tarraconensis. Journal of Roman Archaeology Supplementary Series, 62, 118-132.

ABAD CASAL, L. (2010a): "La Alcudia de Elche. Ayer y hoy de un yacimiento emblemático". Viejos yacimientos, nuevas aportaciones, 173208. MAN, Madrid.

ABAD CASAL, L. (2010b): "Terracotas ibéricas del Castillo de Guardamar". Guardamar. Arqueología y Museo, Catálogo de la exposición, 122-133. Marq, Diputación de Alicante.

ABAD CASAL, L. y BENDALA GALÁN, M. (1994): "La urbanística del mundo ibérico: las nuevas perspectivas", Homenaje al Profesor Antonio García y Bellido. AEspA, 67, 301-304.

ABAD CASAL, L. y BENDALA GALÁN, M. (1997): "Urbanismo y ciudad: de las formaciones ibéricas a la consolidación del modelo romano". XXIII C.N.A. (Elche, 1995), vol. 2, 11-20.

ABAD CASAL, L. y SALA SELLÉS, F. (1993): El poblado ibérico de El Oral (San Fulgencio, Alicante). T.V. del S.I.P., 90. Valencia.

ABAD CASAL, L. y SALA SELLÉS, F. (eds.) (2001): Poblamiento ibérico en el Bajo Segura: El Oral(II) y La Escuera, Bibliotheca Archaeologica Hispana, 12. Madrid.

ABAD CASAL, L. y SALA SELLÉS, F. (2009): “La arquitectura y el urbanismo de El Oral (San Fulgencio, Alicante). Un ejemplo de asimilación de la arquitectura fenicia y púnica". En Sophie Helas y Dirce Marzoli (eds.): Phönizisches und punisches Städtewesen. Iberia Archaeologica, Band, 13, 499-514. 
ABAD CASAL, L., GUTIÉRREZ LLORET S. y GAMO PARRAS, B. (2000): "La ciudad visigoda del Tolmo de Minateda (Hellín, Albacete) y la sede episcopal de Eio". Los orígenes del cristianismo en Valencia y su entorno. Grandes temas arqueológicos, II, 101-112.Valencia.

ABAD CASAL, L., GUTIÉRREZ LLORET, S., GAMO, B. y CÁNOVAS, P. (2011): Guía del Parque Arqueológico Tolmo de Minateda. Hellín.

ABAD CASAL, L., GUTIÉRREZ LLORET, S., GAMO, B. y CÁNOVAS, P. (2012): "El Tolmo de Minateda (Hellín, Albacete, España): un proyecto de investigación y puesta en valor del patrimonio". Debates de Arqueología Medieval, 2.

ABASCAL, J. M. y ABAD CASAL, L. (eds.) (2003): Las ciudades y los campos de Alicante en época romana. Canelobre, 48. Instituto Juan Gil-Albert, Alicante.

ALFÖLDY, A. (2003): “Administración, urbanización, instituciones, vida pública y orden social”. Las ciudades y los campos de Alicante en época romana. Canelobre, 48, 35-57. Instituto Juan GilAlbert, Alicante.

ALFÖLDY, G. (2007): "Fasti und Verwaltung der hispanischen Provinzen: zum heutigen Stand der Forschung“. En R. Haensch y J. Heinrichs (eds.), Herrschen und Verwalten. Der Alltag der römischen Administration in der Hohen Kaiserzeit. Kolloquium zu Ehren von Werner Eck, (Köln, 2005), 325-356. Köln.

AMORÓS ASENSI, V. y CAÑAVATE CASTEJÓN V. (2010): "Transformación funcional de espacios representativos en los inicios del emirato. La basílica y el palacio episcopal de El Tolmo de Minateda". En Ier Congreso Internacional. Espacios urbanos en el Occidente Mediterráneo (ss. VI-VIII), 191-198. Toledo.

ARANEGUI, C. (1995): “Iberia Sacra Loca”. Sur le pas des Grecs en Occident. Collection Etudes Massaliètes, 4, 17-30.

ARANEGUI, C. y VIVES-FERRÁNDIZ, J. (2006): "Encuentros coloniales, respuestas plurales: los ibéricos antiguos de la fachada mediterránea central", De les comunitats locals als estats arcaics: la formació de les societats complexes a la costa del Mediterrani occidental. ArqueoMediterrània, 9, 89-107.

AZUAR RUIZ, R (coord), (2004): El ribat califal. Excavaciones e investigaciones (1984-(1992). Fouilles de la Rábita de Guardamar I, Collection de la Casa de Velázquez, 85. Madrid.

BENDALA GALÁN, M. (2000): Tartesios, iberos y celtas. Temas de hoy. Madrid.

BENDALA GALÁN, M., ABAD CASAL, L., FERNÁNDEZ OCHOA, A. y FUENTES
DOMÍNGUEZ, A. (1987): “Aproximación al urbanismo prerromano y a los fenómenos de transición y de potenciación tras la conquista". Los asentamientos ibéricos ante la romanización, 121-140. Madrid.

BERNABÉU, J., BONET, H. y MATA, C. (1987): "Hipótesis sobre la organización del territorio edetano en época ibérica plena: el ejemplo del territorio de Edeta/Llíria". Iberos, Actas de las I Jornadas sobre el Mundo Ibérico (Jaén, 1985), 137-156. Jaén.

CABALLERO ZOREDA, L. (2000): "La arquitectura denominada de época visigoda ¿es realmente tardorromana o prerrománica?". Visigodos y Omeyas. Un debate entre la Antigüedad Tardia y la Alta Edad Media (I Simposio Internacional de Mérida, 1999). Anejos de AEspA, XXIII, 207-47.

CAÑAVATE CASTEJÓN, V., GUTIÉRREZ LLORET, S. y SARABIA BAUTISTA, J. (e.p): "Cerámica altomedieval en el tolmo de Minateda (Hellín, Albacete, España)". IX Congresso Internazionale AIECM2 (Venezia, 2009).

CASTILLO BELINCHÓN, R. (coord.) (2004): El proyecto europeo ANSER en la Comunidad Valenciana. Memoria de actividades 2003-2004. Diputación de Alicante, Alicante.

De POLIGNAC, F. 1984: La naissance de la cité grecque. Paris.

DOMÉNECH BELDA, C. (2003): Dinares, dírhames y feluses: circulación monetaria islámica en el País Valenciano. Universidad de Alicante, Alicante.

DOMENECH BELDA, C. (2008): "Numismática y arqueología medieval: la moneda de excavación $y$ sus aportaciones". En A. Arévalo González (Coord.): Actas XIII Congreso Nacional de Numismática "moneda y arqueología", vol. 2, 731-760

DOMENECH BELDA, C. (2010): "El proceso de islamización en el Sarq al-Andalus a través de los registros monetales". En Ph. Sénac (ed.): Villa 3. Histoire et archéologie des sociétés de la vallée de l'Ebre (VIIe-XIe siécles), 275-296.

DOMÉNECH BELDA, C. y GUTIÉRREZ LLORET, S. (2006): "Viejas y nuevas monedas en la ciudad emiral de Madînat Iyyuh (El Tolmo de Minateda, Hellin, Albacete)". Al-Qantara, XXVII, fasc.2, 337-374.

EDLUND, I. E. M. (1987): The gods and the place: location and function of sanctuaries in the countryside of Etruria and Magna Graecia (700400 B.C.). Stockholm.

ESPINOSA RUIZ, A. (2006): "Sobre el nombre de la ciudad ibérica y romana de Villajoyosa y la ubicación del topónimo Alonís/Alonai/Allon". Lucentum, XXV, 223-248. 
ESPINOSA RUIZ, A., RUIZ ALCALDE, D. y MARCOS GONZÁLEZ, A. (2005): "Nuevas aportaciones al conocimiento de la Vila Joiosa en época ibérica". En L. Abad, F. Sala y I. Grau (eds.): $L a$ Contestania ibérica, treinta años después, 179198. Alicante.

ESPINOSA RUIZ, A.; SÁEZ LARA, F. y CASTILLO BELINCHÓN, R. (2006): Puertos y navegación en las costas meridionales valencianas (s. I-X d. C.). British Archaeological Reports (B.A.R.), International Series, 1475. Oxford.

ESPINOSA RUIZ, A., RUIZ ALCALDE, D., MARCOS GONZÁLEZ, A. y PEÑA DOMÍNGUEZ, P. (2006): "Nuevos testimonios romano-republicanos en Villajoyosa: un probable campamento militar del s. I a.C.”, en Iberia e Italia: modelos romanos de integración territorial. Actas del IV Congreso Hispano-Italiano (Murcia, 2006), 199220.

FIGUERAS PACHECO, F. (1959): Dos mil años atrás. Las ciudades, el puerto y la necrópolis de La Albufereta. Instituto de Estudios Alicantinos, Alicante.

FRÍAS CASTILLEJO, C. (2010): El poblamiento rural de Dianium, Lucentum, Ilici y la ciudad romana de la Vila Joiosa (siglos II a.c.-VII d.c.). Bases para su estudio. Alicante.

GARCÍA CANO, J. M. (1997): Las necrópolis ibéricas de Coimbra del Barranco Ancho (Jumilla, Murcia). I. Las excavaciones y estudio analítico de los materiales. Murcia.

GARCÍA GANDÍA, J. R. (2009): La necrópolis orientalizante de Les Casetes (La Vila Joiosa, Alicante). Serie Arqueología. Publicaciones de la Universidad de Alicante. Alicante.

GONZÁLEZ PRATS, A. (2010): "La colonia fenicia de La Fonteta", Guardamar del Segura. Arqueología y Museo. Catálogo de la exposición, 66-79. Marq, Alicante.

GRAU MIRA, I. (2002): La organización del territorio en el área central de la Contestania Ibérica, Serie Arqueología. Publicaciones de la Universidad de Alicante. Alicante.

GRAU MIRA, I. (2005): El territorio septentrional de la Contestania". En L. Abad, F. Sala y I. Grau (eds.): La Contestania ibérica, treinta años después, 91-117, Alicante.

GRAU MIRA, I. (2010): "Paisajes sagrados del área central de la Contestania ibérica". En T. Tortosa y S. Celestino (coords.): La expresión religiosa ibérica: proceso de identidades e intercambios en el marco antiguo Mediterráneo. 'Debate en torno a la religiosidad protohistórica', Mérida 2005, 101-122. Anejos de AEspA. Madrid.
GRAU MIRA, I. y OLMOS ROMERA, R. (2005): “El ánfora ática de la Cova dels Pilars (Agres, Alicante): una propuesta de lectura iconográfica en su contexto espacial ibérico". AEspA, 78, 4977.

GRAU MIRA, I. y GARRIGÒS ALBERT, I. (2008): "Aproximació al poblament romà de les Valls d'Alcoi", Recerques del Museu d'Alcoi, 16, 113159.

GUTIÉRREZ LLORET, S., (1996): La Cora de Tudmir: de la antigüedad tardía al mundo islámico, (CCV, 57). Madrid-Alicante.

GUTIÉRREZ LLORET, S. (2000): "La identificación de Madinat Iyyih y su relación con la sede episcopal Elotana. Nuevas perspectivas sobre viejos problemas".En Scripta in Honorem E. A. Llobregat, 481-501. Alicante.

GUTIÉRREZ LLORET, S. (2004): "Ilici en la Antigüedad Tardía. La ciudad evanescente". En Iberia, Hispania, Spania. Una mirada desde Ilici, 95-110. CAM, Alicante.

GUTIÉRREZ LLORET, S. (2006): “Cerámica y escritura: dos ejemplos de arabización temprana. Graffiti sobre cerámica del Tolmo de Minateda (Hellín, Albacete)". En Al-Ândalus. Espaço de mudanza. Balanço de 25 anos de història $e$ arqueología medievais. "Seminario Internacional Homenagem a Juan Zozaya Stabel-Hansen (Mértola, 2005)", 52-60. Mértola.

GUTIÉRREZ LLORET, S. (2007): “La islamización de Tudmir: balance y perspectivas". En Sénac $\mathrm{Ph}$. (ed.): Villa II. Villes et campagnes de Tarraconaise et d'al-Andalus (VIé - XIé siècles): la Transition, 275-318. Etudés Medievales Iberiques.

GUTIÉRREZ LLORET, S. (2008a): “Madînat Iyyuh y la destrucción del espacio urbano en la Alta Edad Media". En Castrum 8, Le château et la ville. Espaces et réseaux" (Baeza, 2002), 199-22. CCV108, Madrid.

GUTIÉRREZ LLORET, S. (2008b): "Los orígenes de Tudmir y el Tolmo de Minateda (siglos VI-X)". En Regnum Murciae. Génesis y configuración del reino de Murcia, 57-71. Comunidad Autónoma de la Región de Murcia, Murcia.

GUTIÉRREZ LLORET, S. (2011a): "Histoire et archéologie de la transition en al-Andalus: les indices matériels de l'islamisation à Tudmir". En D. Valerian (ed.): Islamisation et arabisation de l'Occident musulman, 195-246.

GUTIÉRREZ LLORET, S. (2011b): "El reconocimiento arqueológico de la islamización. Una mirada desde al-Andalus", En 711. Arqueología e Historia entre dos mundos. Zona arqueológica, 15, 2011, vol. I, 191-212. 
GUTIÉRREZ LLORET, S. (2011c): "El Tolmo de Minateda en torno al 711". En 711. Arqueología e Historia entre dos mundos. Zona arqueológica, 15, 2011, vol. I, 355-374.

GUTIÉRREZ LLORET, S. y ABAD CASAL, L. (2002): "Fortificaciones urbanas altomedievales del Tolmo de Minateda (Hellín, Albacete, España): el baluarte occidental". En Mil Anos de Fortificaçôes na Península Ibérica e no Magreb (500-1500). Actas do Simpósio Internacional sobre Castelos, 133-143. Lisboa.

GUTIÉRREZ LLORET, S. y CAÑAVATE CASTEJÓN, V. (2010): “Casas y cosas: espacios $\mathrm{y}$ funcionalidad en las viviendas emirales del Tolmo de Minateda (Hellín, Albacete)". Cuadernos de Madînat al-Zahra, 7 ,125-50.

GUTIÉRREZ LLORET, GAMO PARRAS, B. y AMORÓS ASENSI V. (2003): "Los contextos cerámicos altomedievales del Tolmo de Minateda y la cerámica altomedieval en el sudeste de la Península Ibérica". En L. Caballero, P. Mateos y M. Retuerce (eds.): Cerámicas tardorromanas y altomedievales en la Península Ibérica. Ruptura y continuidad. Anejos de AEspA, XXVIII, 119-168. Madrid.

GUTIÉRREZ LLORET, S. y GRAU MIRA, I. (2012): "El territorio tardoantiguo y altomedieval en el sureste de hispania: Eio - Iyyuh como caso de estudio”. En L. Caballero, P. Mateos y T. Cordero Ruiz, T. (eds.): Visigodos y Omeyas: El territorio. Anejos de AEspA, LVI, 171-198. Mérida.

GUTIÉRREZ LLORET, S. y SARABIA BAUTISTA, J. (2007): "El problema de la escultura decorativa visigoda en el sudeste a la luz del tolmo de Minateda: distribución, tipologías funcionales y talleres". En Luis Caballero Zoreda y Pedro Mateos (coords.): Escultura decorativa tardorromana y altomedieval en la Península Ibérica. Anejos de AEspA, XLI, 301-344.Madrid.

LAFUENTE VIDAL, J. (1957): Alicante en la Edad Antigua. Alicante.

LÓPEZ MONDÉJAR, L. (2008): “La definición de los bastetanos en la historiografía. Enfoques para un estudio del mundo ibérico murciano". En A. Adroher y J. Blánquez, (eds.): Primer Congreso Internacional de Arqueología Ibérica Bastetana. Serie Varia 9, 11-22. Madrid.

LORENZO DE SAN ROMÁN, R. (2006): L'Alcudia d'Elx a l'Antiquitat tardana. Anàlisi historiográfica i arqueologica de l'Illici dels segles V-VIII. Publicacions de l'Universitat d'Alacant. Alacant.

LLOBREGAT CONESA, E. A. (1969): "Hacia una desmitificación de la Historia Antigua de Alicante. Nuevas perspectivas sobre algunos problemas". Revista del Instituto de Estudios Alicantinos, I, 35-55.
LLOBREGAT CONESA, E. A. (1972): Contestania Ibérica. Instituto de Estudios Alicantinos, Alicante.

MARCOS GONZÁLEZ, A. (2010): La villa romana de El Xarquet. Trabajo de doctorado de 9 créditos. Inédito. Universitat d'Alacant.

MARCOS GONZÁLEZ, A. y RUIZ ALCALDE, D. (2005): "Las necrópolis de Poble Nou y de Casetes (sector Creueta). Dos yacimientos ibéricos excepcionales de Villajoyosa”. En J. M. García León y A. Espinosa Ruiz (eds.): I Jornades sobre l'actualitat del patrimoni arqueològic $i$ etnogràfic a la Marina Baixa (Altea, 2004), 73-80. Elx.

MAROT I SALSAS, T. (1997): “Aproximación a la circulación monetaria en la Península Ibérica y las islas Baleares durante los siglos V y VI: la incidencia de las emisiones vándalas y bizantinas". Revue Numismatique, 152, 157-190.

MAROT I SALSAS, T., LLORENS, M. y SALA, F. (2000): “Contextos monetarios del siglo VI: las monedas procedentes de los vertederos del barrio de Benalúa (Alicante)". V Reunió d'Arqueologia Cristiana Hispànica (Cartagena, 1998), 507-517. Barcelona.

MAROT I SALSAS, T. (2002): "La península Ibérica en los siglos V-VI: consideraciones sobre provisión, circulación y usos monetarios". X C.N.N., 71-96. Albacete.

MATA PARREÑO, C. (1995): "Las influencias del mundo fenicio-púnico en los orígenes y desarrollo de la cultura ibérica". En III C.I.E.F.P., II, 225-244. Túnez.

MATEO, M. A. et alii, (2004): "Posidonia oceánica. Un archivo orgánico milenario". En I seminario ANSER: Evolución paleoambiental de los puertos y fondeaderos antiguos en el Mediterráneo occidental, 219-230. Rubettino, Roma.

MORATALLA JÁVEGA, J. (2004-2005): “La Alcudia ibérica: una necesaria reflexión arqueológica”. Lucentum, XXII-XXIII, 89-104.

MORATALLA JÁVEGA, J. (2005): "El territorio meridional de la Contestania". En L. Abad, F. Sala y I. Grau (eds.): La Contestania ibérica, treinta años después, 91-117. Alicante.

MORET, P. (2006): “Architecture indigène et modèles hellénistiques: les ambigüetés du cas ibérique". Pallas, 70, 207-227. Université de Toulouse.

NORDSTRÖM, S. (1961): Los cartagineses en la costa alicantina. Alicante.

OLCINA DOMÉNECH, M. (2005): "La Illeta dels Banyets, El Tossal de Manises y La Serreta". En L. Abad, F. Sala y I. Grau (eds.): La Contestania ibérica, treinta años después, 147-178. Alicante. 
OLCINA DOMÉNECH, M. (ed.) (2009): Lucentum (Tossal de Manises, Alicante). Arqueología e Historia. MARQ, Alicante

OLCINA DOMÉNECH, M. A. (2011): Un paisaje milenario. Parcelación agraria y colonos en Ilici. Catálogo de la exposición del MARQ (MayoSeptiembre 2011). Alicante.

OLCINA DOMÉNECH, M, GUILABERT MAS, A. y TENDERO PORRAS, E. (2010): "Lectura púnica del Tossal de Manises (Alicante)". Mainake, 32 (I), 229-249.

OLCINA DOMÉNECH, M., GRAU MIRA, I., MOLTÓ GISBERT, S., REIG SEGUÍ, C., SALA SELLÉS, F. y SEGURA MARTÍ, J.M. (1998): "Nuevas aportaciones a la evolución de la ciudad ibérica: el caso de La Serreta". En Aranegui, C. (ed.): Actas del Congreso Internacional Los Iberos, Príncipes de Occidente (Barcelona, 1998), 35-46. Barcelona.

OLIVER FOIX, A. (1995): “La presencia púnica en los asentamientos ibéricos: una aproximación a su problemática". III C.I.E.F.P., II, 282-296, Túnez.

PÉREZ BALLESTER, J. y BORREDA, R. (1998), “El poblamiento ibérico del Valle del Canyoles. Avance sobre un proyecto de evolución del paisaje en la comarca de la Costera (Valencia)". Saguntum-PLAV, 31, 133-152.

PÉREZ BALLESTER, J. y BORREDA, R. (2004): "La Carraposa (Rotglá i Corbera-Llanera de Ranes). Un lugar de culto ibérico en el valle del Canyoles (La Costera, Valencia)". Madrider Mitteilungen, 45, 274-320.

PRADOS MARTÍNEZ, F. (2007): “A propósito del pilar-estela ibérico de Monforte del Cid (Alicante). Elementos para una discusión". Habis, $38,79-98$.

PRADOS MARTÍNEZ, F. (2011): "Iberia entre Atenas y Cartago. Una lectura de los pilares-estela". En J. Blánquez (ed.): ¿Hombres o dioses? Una nueva mirada a la escultura del mundo ibérico, 179207. Madrid.

RAMOS MOLINA, A. y TENDERO PORRAS, M. (2000): "Dos nuevos conjuntos termales en Ilici (La Alcudia, Elche)". En Termas romanas en el occidente del imperio: II Coloquio Internacional de Arqueología en Gijón, 245-250. Gijón.

ROUILLARD, P., GAILLEDRAT, E. y SALA, F. (eds.) (2007): L'établissement protohistorique de La Fonteta (fin VIIIe-fin Ve siécle av. J.-C). Casa de Velázquez, Madrid.

ROVELLI, A. (2002): "Roma e il Mediterraneo in età bizantina (VII-VIII secolo). Materialli dallo scavo della Cryta Balbi”. En V Reunió d'Arqueologia Cristiana Hispànica (Cartagena 1998), 415-421. Barcelona.
RUIZ ALCALDE, D. (2010): Las termas públicas del municipium romano de Villajoyosa. Trabajo de doctorado de 9 créditos. Inédito. Universitat d'Alacant.

RUIZ RODRÍGUEZ, A. (2007): "Los Iberos". En F. Gracia (ed.): De Iberia a Hispania, 733-839. Barcelona.

RUIZ RODRÍGUEZ, A. y MOLINOS MOLINOS, M. (2008): "Las fuentes del Guadalquivir. Límites y fronteras para el norte de la Bastetania”. En A. Adrohrer y J. Blánquez (eds.): Primer Congreso Internacional de Arqueología Iberica Bastetana, Varia $n^{\circ}$ 9, 51-72. Madrid.

SALA SELLÉS, F. (2001-2002): "Para una revisión de las relaciones púnicas con la costa ibérica alicantina: nuevas perspectivas sobre algunos viejos problemas". Anales de Prehistoria y Arqueología de la Universidad de Murcia, 17-18, 283-300.

SALA SELLÉS, F. (2004): "La influencia del mundo fenicio y púnico en las sociedades autóctonas del Sureste peninsular". XVIII Jornadas de Arqueología Fenicio-Púnica, 57-102. Ibiza.

SALA SELLÉS, F. (2005): "Púnics al sud del País Valencià: vint-i-cinc anys d'investigació". Fonaments, 12, 21-39.

SALA SELLÉS, F. (2010): "Nuevas perspectivas sobre las relaciones púnicas con la costa ibérica del sureste peninsular". Mainake, 32 (II), 933-950.

SALA SELLÉS, F. y ABAD CASAL, L. (2006): "Arquitectura monumental y arquitectura doméstica en la Contestania”. Lucentum, XXV, 23-46.

SANZ GAMO, R. (1997): La romanización en tierras de Albacete: los siglos de transición. Instituto de Estudios Albacetenses, Albacete.

SARABIA BAUTISTA, J. (2003): Los elementos arquitectónicos ornamentales en el Tolmo de Minateda (Hellín, Albacete). Instituto de Estudios Albacetenses, Albacete.

SCHULTEN, A. 1924 (reed. 2006): Tartessos. Contribución a la historia más antigua de Occidente. Almuzara, Córdoba.

SORIA COMBADIERA, L. (2000): La cultura ibérica en la provincia de Albacete: génesis y evolución a través del estudio del poblamiento. Instituto de Estudios Albacetenses, Albacete.

VERDÚ PARRA, E. (2010): "Sobre la presencia de monedas púnicas en sepulturas de la necrópolis de l'Albufereta (Alicante)". Mainake, 32 (I), 301303. 